\title{
A satellite-based hybrid algorithm to determine the Priestley-Taylor parameter for global terrestrial latent heat flux estimation across multiple biomes
}

Yunjun Yao ${ }^{\mathrm{a}, \mathrm{b},{ }^{*}}$, Shunlin Liang ${ }^{\mathrm{a}, \mathrm{b}, \mathrm{c}}$, Xianglan $\mathrm{Li}^{\mathrm{b}}$, Jiquan Chen ${ }^{\mathrm{d}}$, Kaicun Wang ${ }^{\mathrm{b}}$, Kun Jia $^{\text {a, b }}$, Jie Cheng ${ }^{\text {a, b }}$, Bo Jiang ${ }^{\text {a, b }}$, Joshua B. Fisher ${ }^{\mathrm{e}}$, Qiaozhen Mu ${ }^{\mathrm{f}}$, Thomas Grünwald $^{\mathrm{g}}$, Christian bernhofer ${ }^{\mathrm{g}}$ and Olivier Roupsard ${ }^{\mathrm{h}, \mathrm{i}}$

a. State Key Laboratory of Remote Sensing Science, School of Geography, Beijing Normal University, Beijing, 100875, China

b. College of Global Change and Earth System Science, Beijing Normal University, Beijing, 100875, China

c. Department of Geographical Sciences, University of Maryland, College Park, MD 20742, USA

d. CGCEO/Geography, Michigan State University, East Lansing, MI 48823, USA

e. Jet Propulsion Laboratory, California Institute of Technology, 4800 Oak Grove Dr., Pasadena, CA, 91109, USA

f. Numerical Terradynamic Simulation Group, Department of Ecosystem and Conservation Sciences, The University of Montana, Missoula, MT 59812, USA

g. Technische Universität Dresden, Institute of Hydrology and Meteorology, chair of Meteorology, Pienner Str. 23, 01737 Tharandt, Germany

h. CIRAD, UMR Eco\&Sols (Ecologie Fonctionnelle \& Biogéochimie des Sols et des Agro-écosystèmes), 34060 Montpellier, France

i. CATIE (Tropical Agricultural Centre for Research and Higher Education), 7170 Turrialba, Costa Rica

\section{Remote Sensing of Environment (Revised)}

\section{Reference Number: RSE-D-15-00160}

*Corresponding Author: Yunjun Yao

Beijing Normal University, Beijing, 100875, China

Email: boyyunjun@163.com

Tel: $86+10-5880-3002$

May 6, 2015 


\begin{abstract}
Accurate estimation of the terrestrial latent heat flux $(L E)$ for each plant functional type $(P F T)$ at high spatial and temporal scales remains a major challenge. We developed a satellite-based hybrid algorithm to determine the Priestley-Taylor (PT) parameter for estimating global terrestrial $L E$ across multiple biomes. The hybrid algorithm combines a simple empirical equation with physically based ecophysiological constraints to obtain the sum of the weighted ecophysiological constraints $(f(e))$ from satellite-based Normalized Difference Vegetation Index $(N D V I)$ and ground-measured air temperature $\left(T_{a}\right)$, relative humidity $(R H)$, vapor pressure deficit (VPD) and $L E$ for 2000 to 2009 provided by 240 globally distributed FLUXNET eddy covariance (ECOR) tower sites. Cross-validation analysis indicated that the optimization at a PFT level performed well with a RMSE of less than 0.15 and a $R^{2}$ between 0.61 and 0.88 for estimated monthly $f(e)$.Cross-validation analysis also revealed good performance of the hybrid-based $P T$ method in estimating seasonal variability with a $R M S E$ of the monthly $L E$ varying from $4.3 \mathrm{~W} / \mathrm{m}^{2}$ (for 6 deciduous needleleaf forest sites) to $18.1 \mathrm{~W} / \mathrm{m}^{2}$ (for 34 crop sites) and with a $R^{2}$ of more than 0.67. The algorithm's performance was also good for predicting among-site and inter-annual variability with a $R^{2}$ of more than 0.78 and 0.70 , respectively. We implemented the global terrestrial $L E$ estimation from 2003 to 2005 for a spatial resolution of $0.05^{\circ}$ by recalibrating the coefficients of the hybrid algorithm using Modern Era Retrospective Analysis for Research and Applications (MERRA) meteorological data, Moderate Resolution Imaging Spectroradiometer (MODIS) NDVI product and ground-measured $L E$. This simple but accurate hybrid algorithm provides an alternative method for mapping global terrestrial $L E$, with a performance generally improved as compared to other satellite algorithms that are not calibrated with tower. The calibrated $f(e)$ differs for different $P F T$ s, and all driving forces of the algorithm can be acquired from satellite and meteorological observations.
\end{abstract}

Keywords: Global latent heat flux; Hybrid algorithm; Plant functional type; Priestley-Taylor parameter; Ecophysiological constraints 


\section{Introduction}

Terrestrial latent heat flux $(L E)$, the flux of heat from the Earth's surface to the atmosphere for the processes of water evaporation and vegetation transpiration, is an important component of the Earth's surface energy budget and a key process in land surface-atmosphere interactions (Jung et al., 2010; Liang et al., 2010; Mu et al., 2011; Vinukollu et al., 2011a, 2011b; Wang et al., 2010a, 2010b; Wang \& Dickinson, 2012). Accurate detection of spatio-temporal variations of $L E$ with high accuracies at regional or global scales is essential for understanding the global water cycle and carbon uptake through photosynthesis. Since the 1990's, the eddy covariance (ECOR) flux measurements provided by FLUXNET projects have been considered to be a good micrometeorological method to measure $L E$ exchanges between the atmosphere and terrestrial ecosystems(Baldocchi et al., 2001; Fisher et al., 2008; Liu et al., 2011, 2013; Twine et al., 2000; Yuan et al., 2010). However, it is still difficult to estimate $L E$ at a regional scale because the spatial representation of sparse point $L E$ estimates is questionable due to the complex heterogeneity of terrestrial ecosystems.

Satellite remote sensing has greatly improved global scale estimates of land surface variables (Liang et al., 2012) (e.g., surface solar radiation $\left(R_{S}\right)$, net radiation $\left(R_{n}\right)$, land surface temperature $\left(T_{s}\right)$, leaf area index $(L A I)$, vegetation index $(V I)$, albedo and biome type) that are linked to $L E$ (Los et al., 2000; Mu et al., 2007; Wang et al., 2007). In general, satellite-based $L E$ algorithms integrate satellite and meteorological observations to estimate regional $L E$ for providing spatially distributed $L E$ datasets. During the past few decades, many satellite-based $L E$ algorithms have 
been characterized by the parallel development of empirical/statistical algorithms that lack dynamics of evapotranspiration (ET) process (Jackson et al., 1977; Jin et al., 2011; Jung et al., 2011; Wang \& Liang, 2008; Yang et al., 2006; Yao et al., 2011) and complicated physical models that contain realistic mechanisms (Allen et al., 2007; Anderson et al., 1997; Bastiaanssen et al., 1998; Fisher et al., 2008; Kustas \& Norman, 1996; Miralles et al., 2011; Monteith, 1965; Mu et al., 2011; Norman et al., 1995; Priestley \& Taylor, 1972; Yao et al., 2013). Therefore, the developmental trend of $L E$ algorithms has tended to increased applicability, as opposed to complexity (Federer et al., 1996; Fisher et al., 2008).

Satellite-based empirical/statistical $L E$ algorithms have been scaled up from site to regional scales by relating observed $L E$ to satellite-based vegetation parameters and other key meteorological variables (Wang et al., 2007). Long-term ground measurements from the Atmospheric Radiation Measurement (ARM) and FLUXNET projects have provided an opportunity to develop a series of empirical/statistical $L E$ algorithms (Wang \& Liang, 2008; Wang et al., 2007, 2010a, 2010b). Other data-driven methods, such as model tree ensembles (MTE) (Jung et al., 2010), support vector machine (SVM) (Yang et al., 2006) and artificial neural network (ANN) (Lu \& Zhuang, 2010), are also used to build relationships between system inputs $\left(R_{n}, L A I, V I\right.$ and $T_{a}$ ) and outputs $(L E)$ using training data sets that are representative of all the behaviors found in the systems (Chen et al., 2014). Although these empirical algorithms have a comparable accuracy with other more complicated physical methods (Jiménez et al., 2011; Mueller et al., 2011), they require further recalibration 
for different biomes due to their limited training data at certain sites. Much effort has been dedicated to proposing universal empirical $L E$ algorithms that are suitable for multiple biomes, as reviewed in the literature (Kalma et al., 2008; Wang et al., 2007, 2010a, 2010b; Yuan et al., 2010; Zeng et al., 2014). However, the evaporation fraction $(E F)$, the ratio of $L E / R_{n}$, differs greatly in different biomes due to physiological differences under similar environmental conditions (Bettes et al., 2007; Margolis \& Ryan, 1997). Therefore, there are large errors in the estimated $L E$ from the universal empirical $L E$ algorithms when land cover types are ignored.

Satellite-based physical $L E$ algorithms have been developed to estimate $L E$ based on the Monin-Obukhov Similarity Theory $(M O S T)$ and the Penman-Monteith (PM) equation driven by satellite and meteorological observations (Wang and Dickinson, 2012). The traditional one- and two-source models (Kustas \& Daughtry, 1990; Shuttleworth \& Wallace, 1985), such as the Surface Energy Balance System (SEBS) (Su, 2002), the Surface Energy Balance Algorithm for Land (SEBAL) algorithm (Bastiaanssen et al., 1998), the Satellite-Based Energy Balance for Mapping Evapotranspiration with Internalized Calibration (METRIC)-Model (Allen et al., 2007) and the Two-Source LE Model coupled with Atmosphere-Land Exchange Inverse (ALEXI) model (Anderson et al., 1997; Norman et al., 1995), use surface air temperature gradients $\left(T_{s}-T_{a}\right)$ or time series of satellite-retrieved $T_{s}$ to obtain sensible heat flux $(H)$ and $L E$ (Tang $\& \mathrm{Li}, 2015)$. Yet, the use of $T_{s}$ in the energy residual equation to estimate regional or global terrestrial $L E$ will lead to greater than $50 \%$ errors because advection of $H$ from the surrounding landscape influences the 
calculation of $H$ and $L E$ at a given time and place (Gowda et al., 2008; Stewart et al., 1994; Zhang et al., 2010a, 2010b). To overcome this problem, Mu et al (2011) revised a beta version (Mu et al., 2007) developed from the Cleugh et al. (2007) version of the $P M$ method to estimate global terrestrial $L E$. That algorithm considered the differences of surface resistance for different biomes and was updated to generate the Moderate Resolution Imaging Spectroradiometer (MODIS) LE product (MOD16) driven by MODIS LAI, albedo and land cover, and the Modern-Era Retrospective Analysis for Research and Applications (MERRA) data provided by the National Aeronautics and Space Administration (NASA) Global Modeling and Assimilation Office (GMAO) (Mu et al., 2011). However, the sensitivity of these $P M$ algorithms to the parameterization of resistances and error propagation through complicated calculations will lead to lower accuracy compared with other $L E$ algorithms using empirical formulation of the evaporative process (Ershadi et al., 2014; Fisher et al., 2009).

An alternative approach, the Priestley-Taylor $(P T)$ algorithm, is a simplified $P M$ method that avoids parameterizations of aerodynamic and surface resistance without decreasing the accuracy of the $L E$ estimates (Fisher et al., 2008; Jin et al., 2011; Priestley and Taylor, 1972; Yao et al., 2013). The PT algorithm uses a coefficient multiplier (also named the $P T$ parameter, $\alpha$ ) to replace the atmospheric demand and surface resistance. In general, $\alpha$ can range from 0 (no water) to 1.26 (wet surface) and varies with soil moisture and plant condition in different regions (Brutsaert \& Chen, 1995; Detto et al., 2006; Sumner \& Jacobs, 2005). Currently two types of 
algorithms have been developed to determine $\alpha$ for regional $L E$ estimation using remote sensing and meteorological observations: (1) $T_{s^{-}}$VI triangular methods which use the spatial variation of $T_{s}$ (or day-night $T_{s}$ difference, $\Delta T_{s}$ ) and normalized difference vegetation index (NDVI) to interpolate $\alpha$ and $E F$ for $L E$ estimation (Jiang \& Islam, 2001; Price, 1990; Tang et al., 2010; Wang et al., 2006), and (2) ecophysiological constraint methods that use the $\alpha$ of the potential $L E$ to multiply ecophysiological constraints, such as $L A I, T_{a}$, soil moisture, and vegetation moisture, to estimate actual $L E$ (Fisher et al., 2008; Jin et al., 2011; Miralles et al., 2011). $T_{s^{-}}-V I$ triangular methods have been widely used to estimate regional $L E$ because they only require $T_{s}$ and $N D V I$ derived from remote sensing data without any auxiliary data. Yet these methods do not fully consider the impacts of $T_{s^{-}} V I$ on different land cover types that have different aerodynamic resistance (Carlson, 2007), and thus lack robustness at the global scale. Although the $P T$ algorithms based on ecophysiological constraints (i.e., Fisher et al., 2008) have higher performance when compared to $P M$ methods due to their excellent representation of universal physical governing laws, as well as partitioning of total evaporation, these approaches are applied uniformly across the globe, thus ignoring the differences of ecosystem types to which further calibration and optimization could result in even better estimates (Ershadi et al., 2014; Fisher et al., 2008, 2009; Jin et al., 2011; Miralles et al., 2011; Yao et al., 2013).

In this study, to reduce uncertainties in global $L E$ estimation using the universal empirical $L E$ algorithms or the universal $\alpha$ parameterization of $P T$ algorithms, we developed an optimized hybrid algorithm to determine the $P T$ parameter for global 
terrestrial $L E$ estimation across multiple biomes by combining a simple empirical equation with physically based ecophysiological constraints (i.e., PT-JPL: Fisher et al., 2008) calibrated to measurements from global eddy covariance, satellite and meteorological observations. The objectives of this study are to (1) describe this satellite-based hybrid algorithm for parameterization of the $P T$ parameter to obtain the sum of the weighted ecophysiological constraints $(f(e)) ;(2)$ evaluate the hybrid-algorithm and the corresponding $P T$ method based on a series of cross-validations across multiple biomes using global long-term FLUXNET measurements from 240 flux tower sites; and (3) revise the coefficients of the hybrid algorithm using MODIS data and MERRA meteorological data for estimating annual global terrestrial $L E$ averaged over the period of 2003 to 2005 with a spatial resolution of $0.05^{\circ}$ across multiple biomes.

\section{Data}

\subsection{Data at eddy covariance flux tower sites}

Ground-measurements of eddy covariance $(E C O R)$ were used to validate and evaluate algorithm performance. Data from 240 ECOR flux tower sites, including those from LathuileFlux, AsiaFlux, AmeriFlux, the Asian Automatic Weather Station Network (ANN) Project supported by the Global Energy and Water Cycle Experiment (GEWEX) Asian Monsoon Experiment (GAME ANN), the Coordinated Enhanced Observation Network of China $(C E O P)$ and some individual principal investigators (PIs) of the FLUXNET project were used in this study. These sites are mainly distributed in North America, Asia and Europe, with only 5 sites in Africa, 5 in 
Australia and 7 in South America (Amazon region) (Fig.1). These sites covered 9 major global terrestrial biomes: cropland (CRO; 34 sites), savanna ( $S A W ; 10$ sites), shrubland (SHR; 14 sites), evergreen needleleaf forest (ENF; 64 sites), evergreen broadleaf forest $(E B F ; 16$ sites), deciduous needleleaf forest ( $D N F ; 6$ sites), deciduous broadleaf forest ( $D B F ; 28$ sites), and grass and other types (GRA; 56 sites). The data include half-hourly or hourly incoming solar radiation $\left(R_{s}\right)$, soil heat flux $(G), R_{n}, T_{a}$, vapor pressure deficit $(V P D)$, relative humidity $(R H), H$ and $L E$. Gaps in the data were filled using the method described in Reichstein et al. (2005) that utilizes both the co-variation of fluxes with meteorological variables and the temporal autocorrelation of fluxes. The half-hourly or hourly $L E, H$ and meteorological variables were subsequently aggregated into daily and monthly means. If missing data was more than $25 \%$ of entire data at a given day, the value of this day was indicated as missing. Otherwise daily values were obtained by multiplying averaged hourly rate by 24 (hours). Similarly, monthly values were obtained by multiplying averaged daily rate by 30 or 31 (days). When missing data was more than $25 \%$ of entire month data, the monthly values were also indicated as missing. The data cover the period from 2000 through 2009, and each flux tower has at least one year's worth of data.

Because the ECOR method suffers an energy imbalance problem, where the measured available energy $\left(R_{n}-G\right)$ is greater than the sum of the measured $L E$ and $H$ (Foken, 2008; Jung et al., 2010; Wilson et al., 2002), we corrected the measured LE based on the fixed Bowen ratio method proposed by Twine et al. (2000):

$$
L E_{c}=\frac{L E_{o}}{R_{c}}
$$




$$
R_{c}=\frac{L E_{o}+H_{o}}{R_{n}-G}
$$

where $L E_{c}$ is the corrected latent heat flux, $L E_{o}$ and $H_{o}$ are the uncorrected latent heat flux and sensible heat flux, respectively. $R_{c}$ is the energy closure ratio.

Fig. 1 HERE

\subsection{Satellite and reanalysis datasets}

To develop and revise this satellite-based hybrid algorithm for global terrestrial $L E$ estimation, in this study we used a MODIS global 16-day NDVI product (MOD13A2) with a 1-km spatial resolution, which was downloaded from the Oak Ridge National Laboratory Distributed Active Center (ORNL DAAC) website (http://daac.ornl.gov/MODIS/). The daily NDVI values were temporally interpolated from the 16-day averages using linear interpolation. We only used the NDVI values of pixels that covered the flux tower sites and used the quality control $(Q C)$ flags to exclude the poor quality, cloud contaminated $N D V I$. We also used MERRA reanalysis meteorological data $\left(R_{n}, T_{a}, R H\right.$ and $\left.V P D\right)$ with spatial resolution of $1 / 2^{\circ} \times 2 / 3^{\circ}$ provided by the NASA GMAO (Global Modeling and Assimilation Office, 2004). Detailed information on the MERRA dataset can be downloaded from the website (http://gmao.gsfc.nasa.gov/research/merra).The MERRA data were spatially interpolated to $1 \mathrm{~km}$ using the method described in Zhao et al. (2005) that exploits a cosine function and the four GMAO-MERRA cells to smooth sharp changes in a pixel.

To estimate global terrestrial $L E$ at a spatial resolution of 0.05 degree from 2003 to 2005, we also used the method described in Zhao et al. (2005) to interpolate the MERRA data to 0.05 degrees. We also used the Collection 5 MODIS NDVI 
$\left(M O D 13 C 1: C M G, 0.05^{\circ}\right)$ product (Huete et al., 2002) and Collection 4 MODIS land cover $\left(M O D 12 C 1: C M G, 0.05^{\circ}\right)$ product (Friedl et al., 2002) to drive the hybrid algorithm for global $L E$ estimation across multiple biomes. We filled in the missing and unreliable $N D V I$ at 0.05 -degree spatial resolution using the method described by Zhao et al. (2005).

\section{Methods}

\subsection{Hybrid algorithm-based Priestley-Taylor model logic}

We developed an algorithm from the PT model of (Fisher et al., 2008; Priestley \& Taylor, 1972):

$$
L E=\phi \frac{\Delta}{\Delta+\gamma} f(e)\left(R_{n}-G\right)
$$

where $L E$ is the latent heat flux in $\mathrm{W} / \mathrm{m}^{2}, \phi$ is the $P T$ coefficient for a wet surface condition (1.26) and represents the maximum value of $\alpha, \Delta$ is the slope of the saturated vapor pressure curve $\left(\mathrm{KPa}^{\circ} \mathrm{C}^{-1}\right), \gamma$ is the psychrometric constant $(\mathrm{KPa}$ $\left.{ }^{o} C^{-1}\right), R_{n}$ and $G$ are the surface net radiation and soil heat flux in $\mathrm{W} / \mathrm{m}^{2}$, respectively, and $f(e)$ is the sum of the weighted ecophysiological constraints to determine the $P T$ parameter by multiplying $\phi$, which can be calculated using atmospheric moisture and vegetation indices (Fisher et al., 2008; Yao et al., 2013). The value of $f(e)$ varies from 0 to 1 . Accurate parameterization of $f(e)$ is a tough problem because it is difficult to characterize the dynamics of the ET process based on the limited data. Considering that energy, water and temperature are the three key potential constraints that drive soil evaporation and vegetation transpiration and that the $P T$ model includes an energy term $\left(R_{n}-G\right)$, we introduce a simple empirical linear combination of air 
temperature and physical-based water parameters to estimate $f(e)$.

$$
\begin{gathered}
f(e)=a_{0}+a_{1} f\left(T_{a}\right)+a_{2} f(m) \\
f(m)=b_{0}+b_{1} f(\text { em })+b_{2} f(\text { tm })+b_{3} f(w s)+b_{4} f(\mathrm{im})
\end{gathered}
$$

where $a_{i}(i=0, \ldots, 2)$ and $b_{i}(i=0, \ldots, 4)$ are empirical coefficients, $f\left(T_{a}\right)$ is the temperature constraint, and $f(m)$ is the moisture constraint, which can be considered to be a linear equation of unsaturated soil moisture constraint $f(\mathrm{em})$, vegetation transpiration moisture constraint $f(t m)$, saturated soil moisture constraint $f(w s)$ and canopy interception moisture constraint $f(\mathrm{im})$. In our $P T$ algorithm, both $f(w s)$ and $f(\mathrm{im})$ represent the maximum $L E$ with sufficient water conditions, namely,

$$
\begin{aligned}
& f(w s)=1 \\
& f(i m)=1
\end{aligned}
$$

$f\left(T_{a}\right)$ for both surface soil and vegetation follows the empirical equation detailed by Wang et al. (2007):

$$
f\left(T_{a}\right)=c_{0}+c_{1} T_{a}
$$

where $c_{i}(i=0,1)$ is the empirical coefficient. $f(\mathrm{em})$ is mainly controlled by soil moisture. In our algorithm, we chose $R H^{V P D}$ as introduced by Fisher et al. (2008) to parameterize $f(\mathrm{em})$ based on the complementary hypothesis that surface moisture status is linked to the evaporative demand $(E D)$ of the atmosphere, indicating that soil moisture is characterized by the adjacent atmospheric moisture (Bouchet, 1963; Fisher et al., 2008). Thus, $f(\mathrm{em})$ can be expressed as:

$$
f(e m)=d_{0}+d_{1} R H^{V P D}
$$


where $d_{i}(i=0,1)$ is the empirical coefficient. $f(t m)$ is closely related to vegetation canopy conductance $\left(g_{s}\right)$. According to previous studies, $g_{s}$ mainly depends on photosynthetic leaf area, plant moisture, $T_{a}$ and VPD (Jarvis 1976; Mu et al., 2007, 2011; Wang \& Dickinson, 2012). In our algorithm, we used satellite-based $N D V I$ and $V P D$ to parameterize $f(t m)$, because $N D V I$, which has no model-related errors, is sensitive to $L A I$, and $\left(e_{1} N D V I-e_{2}\right) V P D$ is used to reduce the maximum $g_{s}$ when VPD is high enough to inhibit photosynthesis (Leuning, 1995; Misson et al., 2004; Mu et al., 2007; Xu \& Baldocchi, 2003; Wang et al., 2010a, 2010b), such that:

$$
f(t m)=e_{0}+\left(e_{1} N D V I-e_{2}\right) V P D
$$

where $e_{i}(i=0, \ldots, 2)$ is the empirical coefficient. Eq.(10) shows that $f(\mathrm{tm})$ is diagnosed by the NDVI and $V P D$ terms, and the temperature terms are directly included in $f(e)$. Combining Eqs. (3)-(10), we simplify these empirical coefficients and obtain the hybrid algorithm-based $P T$ equation:

$$
L E=\phi \frac{\Delta}{\Delta+\gamma}\left(R_{n}-G\right)\left[k_{0}+k_{1} T_{a}+k_{2} R H^{V P D}+\left(k_{3} N D V I-k_{4}\right) V P D\right]
$$

$k_{i}(i=0, \ldots, 4)$ are the empirical coefficient. For simplicity, we assumed that $f(s m)=R H^{V P D}$ and $f(v m)=\left(k_{3} N D V I-k_{4}\right) V P D$. We also estimated $G$ based on a simple statistical method driven by fractional vegetation cover $\left(f_{c}\right)$ and $R_{n}$ (Halliwell \& Rouse, 1987; Rouse, 1984; Yao et al., 2013; Zhang et al., 2009):

$$
\begin{gathered}
G=a_{g}\left(1-f_{c}\right) R_{n}(12) \\
f_{c}=\frac{N D V I-N D V I_{\min }}{N D V I_{\max }-N D V I_{\min }}
\end{gathered}
$$


where $a_{g}$ is a constant (0.18). NDVI $I_{\max }$ and $N D V I_{\min }$ are the maximum and minimum NDVI during the study period and are set as invariant constants: 0.95 and 0.05, respectively (Tucker, 1979; Zhang et al., 2009). $f_{c}$ will be replaced by one of the satellite products that are based on more sophisticated estimation algorithms (Liang, et al., 2012; Jia et al., 2014).

Advantages offered by the hybrid algorithm-based $P T$ method over other complicated physical $L E$ models are that 1) it is easy to operate for routine, long-term mapping of $L E$ because it only requires $R_{n}, T_{a}, N D V I, R H$ and $V P D$ and avoids wind speed (WS) and soil moisture. Reliable soil moisture and WS measurements that are required to parameterize $L E$ in many algorithms are unavailable at large scales (Gao \& Dirmeyer, 2006; McVicar et al., 2012; Wagner et al., 2003); 2) it reduces the errors in the required forcing data by avoiding the use of the temperature or humidity differences and by overcoming use of the computational complexities of aerodynamic and surface resistance (Wang \& Dickinson, 2012); and 3) it considers the differences in the coefficients of the Eq. (11) for different PFTs to improve the accuracy of LE estimation.

\subsection{Cross validation}

The parameters of the Eq. (11) were calibrated by linear regression using the observed data (EC ground-measured data and MODIS NDVI product) collected from a sufficient number of representative flux towers. To validate the estimated $f(e)$ and $L E$ accuracy, we evaluated the performance of the satellite-based hybrid algorithm and the corresponding $P T$ model using a five-fold cross validations method, which 
randomly stratified the data set into five groups with approximately equal numbers of samples (Jung et al., 2011). We independently validated the estimated $L E$ for each of the five groups based on the calibrated coefficients of Eq.(11), using data from the remaining four groups. We performed the optimizations for the parameters in Eq. (11) for each PFT. The optimization is based on the least square method to minimize the difference between the estimated $f(e)$ using satellite and meteorological forcing data and the observed $f(e)$ inverted from Eq. (3) using ground-observed $L E, T_{a}, R_{n}$ and $G$ from flux tower sites. We also summarized the squared correlation coefficients $\left(R^{2}\right)$, root mean square error $(R M S E)$, bias and $p$ values of the estimated $f(e)$ and $L E$ and those derived from the flux tower data to demonstrate the relative predictive errors.

To evaluate the ability of our method to predict the spatio-temporal variations in $L E$, we used the observed and estimated data to test three categories of $L E$ variability: (1) seasonal variation, (2) among-site variation, and (3) annual anomalies. We first performed a series of cross-validations of $L E$ seasonal cycle by comparing the daily (monthly) estimated $L E$ and the observed $L E$. To test the among-site variation, we validated the average values of the measured and predicted $L E$ at each site over the entire period. To assess how well the model predicts long-term variations in $L E$, we averaged the measured and predicted $L E$ into annual values at each site and removed the multiyear average from the annual values to acquire annual $L E$ anomaly for each site. We chose flux tower sites that had at least three years' worth of data.

For comparison with $L E$ estimates based on the other algorithms, we used a 
simple holdout method that randomly divided the data set into two groups with approximately equal numbers of samples (Yao et al., 2014a). We validated daily $L E$ using data from the first group based on the calibrated coefficients of Eq.(11) using data from the second group and we then validated daily $L E$ using data from the second group based on the calibrated coefficients of Eq.(11) using data from the first group.

\subsection{Comparison with other LE algorithms}

\subsubsection{MOD16 LE algorithm}

A MOD16 global $L E$ retrieval algorithm is based on the well-established Penman-Monteith logic (Monteith, 1965) with modifications to account for parameters not readily available from space (Cleugh et al., 2007). The MOD16 algorithm accounts for both surface energy partitioning and environmental constraints on $E T$, and includes canopy interception evaporation, evaporation from wet/moist soil surfaces, and transpiration through vegetation pores (stomata). Atmospheric relative humidity $(R H)$ is used to quantify the proportion of wet soil and wet canopy components (Fisher et al., 2008). Proportional vegetation cover is derived from MODIS fractional absorbed photosynthetically active radiation (FPAR) (Los et al., 2000), and used to partition net radiation $\left(R_{n}\right)$ between vegetation and soil surfaces. Leaf level stomatal conductance is determined by the mean daytime surface air vapor pressure deficit $(V P D)$ and daily minimum air temperature $\left(T_{\min }\right)$, and further up-scaled to the non-wet canopy level using the MODIS leaf area index (LAI) product (MOD15A2). Using the complementary relationship hypothesis (Fisher et al., 2008), soil evaporation is estimated as the potential evaporation rate for wet soil surfaces 
scaled down by $R H$ and $V P D$ for moist soil conditions. The daily $L E$ calculation represents the 24 hour sum of $L E$ from the daytime and nighttime (largely minimal) calculations. MOD16 LE algorithm was validated at 46 flux tower sites and agreed with the $L E$ measurements well (Mu et al., 2011). Considering that most $L E$ occurs during daytime, our proposed $P T$ algorithm in this study only estimated daytime $L E$ and neglected nighttime $L E$. Therefore, we only used MOD16 algorithm to estimate daytime $L E$.

\subsubsection{PT-JPL LE algorithm}

A Priestley-Taylor-based (PT-JPL) LE algorithm was introduced by Fisher et al. (2008), based on the $P T$ equation to downscale potential $L E$ to actual $L E$ by adding both atmospheric (RH and VPD) and ecophysiological constraints (FPAR and LAI). $P T-J P L$ estimates $L E$ by calculating the sum of the soil evaporation, the canopy transpiration and the canopy interception evaporation. The validation at the 39 global flux tower sites illustrates that the averaged $R M S E$ of the estimated and observed $L E$ is $15.2 \mathrm{~W} / \mathrm{m}^{2}$ with an $R^{2}$ of 0.9 (Fisher et al., 2008, 2009). PT-JPL has been independently demonstrated as the highest performing physically based global remote sensing $L E$ algorithm in multi-algorithm intercomparisons (Chen et al., 2014; Ershadi et al., 2014; Vinukollu et al., 2011).

\section{Results}

\subsection{Optimization of the PT parameter}

To parameterize the $P T$ parameter, we used $f(e)$ to replace the original $P T$ parameter because $f(e)$ is a suitable ecophysiological index for the temporal scaling. 
To determine the factors that drive the variation of $f(e)$, we analyzed the variations of the combined variables from ground-measured $T_{a}, R H, V P D$ and MODIS NDVI from all of the flux tower sites. Fig. 2 gives an example of the temporal variation of the 8-day $f(e)$ estimated directly from observations during January 2002-December 2006 at the Au-How site using Eq. (3) together with $T_{a}, f(s m)$ and $f(v m)$. Both $f(\mathrm{sm})$ and $f(\mathrm{vm})$ have an obvious seasonal pattern in this savanna that was similar to $f(e)$ and have high correlations with $f(e)$ at all of the flux tower sites. Although the variation of $T_{a}$ also follows that of $T_{a}, T_{a}$ has a relatively lower correlation with $f(e)$ at all of the flux tower sites because $\Delta /(\Delta+\gamma)$ directly included $T_{a}$. Therefore, soil moisture and vegetation moisture were the largest contributors to the variations in $f(e)$.

\section{Fig.2 HERE}

Figs 3 and 4 show the correlations of monthly observed $f(e)$ directly inverted from observations using Eq. (3) with monthly $f(s m)$ and $f(v m)$ for different biomes, respectively. Generally speaking, variations in monthly $f(\mathrm{sm})$ explained $25 \%$ to $82 \%$ of the variance in monthly $f(e)$ at all sites. The correlation coefficients between $f(e)$ and $f(s m)$ vary from $0.56(p<0.01)$ at all $M F$ sites to $0.87(p<0.01)$ at all $S A W$ sites. The correlations between $f(e)$ and $f(s m)$ in both all $G R A$ and $S A W$ sites are higher than $0.78(p<0.01)$, yet $f(s m)$ was not always the best predictor of $f(e)$ in the $C R O$ and forest (excluding $E B F$ ) ecosystems. Therefore, $f(s m)$ captures the variations in surface soil evaporation for different PFTs because surface soil moisture can sustain the transpiration of sparse vegetation (e.g., grass and savanna) and cannot 
provide supply water for the transpiration of dense vegetation (e.g., forests). As expected, $f(v m)$ also explains much of the variance of $f(e)$ in most obvious seasonal biomes, and $f(v m)$ is highly correlated with $f(e)$ for deciduous forests, shrub, crop and grass sites. For instance, the correlation coefficient between $f(\mathrm{vm})$ and $f(e)$ is $0.89(p<0.01)$ at all $D N F$ sites and $0.78(p<0.01)$ at all $S H R$ sites. Thus, $f(v m)$ characterizes the vegetation transpiration across multiple biomes by a combination of $N D V I$ and $V P D$ because $N D V I$ is used to monitor the seasonal variation of vegetation growth and $V P D$ reflects the negative effects of vegetation photosynthesis.

\section{Fig. 3 HERE}

\section{Fig. 4 HERE}

Table 1 shows the parameters of Eq. (11) for nine different biomes by linear regression based on the satellite-based $N D V I$, ground-measured $T_{a}, R H, V P D$ and $f(e)$. Our proposed hybrid algorithm yields different values of $f(e)$ for each PFT. For example, in July, GRA and $C R O$ had the largest estimated $f(e)$ (approximately 0.85), followed by $D N F, D B F, S A W, E B F, S H R$, while $E N F$ and $M F$ had the minimum $f(e)$. $f(v m)$ by integrating $N D V I$ and $V P D$ is highly correlated to $L E$ in all biomes and $f(e)$ increased as a function of $f(\mathrm{vm})$ with vegetation growth. $f(\mathrm{sm})$ affected $f(e)$ significantly for non-forests, and $L E$ for forests was not dependent on surface moisture.

Table 1 HERE

The sensitivity experiments used to determine the dependence of $f(e)$ on $T_{a}, R H$ 
and NDVI are shown in Fig. 5. The $f(e)$ at different biomes vary by less than 0.3 with the increasing $T_{a}$ from 5 to $30^{\circ} \mathrm{C}$ when other input variables are set as constants $(R H=0.7 ; N D V I=0.7)$. In response to the same changes in $T_{a}$, the estimated $f(e)$ at the $D N F$ sites varies the most compared with those at other biomes sites. Similarly, the estimated $f(e)$ varies by less than 0.5 for a 0.8 change in $R H$ and NDVI at most PFT sites. However, at $M F$ sites, $f(e)$ increase by more than 0.5 for a 0.8 increase in $R H$ and NDVI. Therefore, both $R H$ and NDVI have a significant influence on $f(e)$, and $f(e)$ is less sensitive to the error in $T_{a}$ but cannot be neglected.

Fig. 5 HERE

\subsection{Algorithm evaluation}

\subsubsection{Algorithm performance based on cross validation}

We performed a series of cross validations to evaluate the performance of our satellite-based algorithm for monthly $f(e)$ at different PFTs. Fig. 6 shows the comparison of estimated and observed monthly $f(e)$ at nine biomes. It is clear that the performance varies with the biomes and criteria (bias, $R M S E$ and $R^{2}$ ). The RMSE between estimated $f(e)$ and observed $f(e)$ are all less than 0.15 , and the $R^{2}$ ranges from 0.61 to 0.88 ( $99 \%$ confidence). The hybrid algorithm has the highest performance, with an RMSE of 0.07 and an $R^{2}$ of $0.86(p<0.01)$ at the DNF sites, followed by at $S A W, S H R, G R A, D B F, E B F, M F$ and $C R O$ sites. However, the worst performances, with an $R^{2}$ of $0.55(p<0.01)$, occur at the $E N F$ sites. In general, the few samples at the DNF sites led to the relative higher accuracy of $f(e)$ estimation. Perhaps when there are equal numbers of samples at the different biomes, the 
algorithm will have lower accuracy of $f(e)$ at dense forests sites due to the saturation effect of NDVI. We consider the overall performance of our algorithm at different PFTs is satisfying for estimating the $P T$ parameter.

\section{Fig.6 HERE}

Estimated $L E$ based on our $P T$ model driven by tower-specific meteorology and MODIS NDVI product was also cross-validated. A comparison of the measured and estimated daily (monthly) $L E$ at the site scale for each $P F T$ demonstrates that our $P T$ algorithm accurately estimates seasonal $L E$ (Fig. 7). At the PFT level, the RMSE of the estimated monthly (daily) $L E$ varies from $4.3(11.5) \mathrm{W} / \mathrm{m}^{2}$ for all $D N F$ sites to $18.1(20.9) \mathrm{W} / \mathrm{m}^{2}$ for all $C R O$ sites and the $R^{2}$ (99\% confidence) varies from 0.80 (0.68) for all $S H R$ sites to $0.96(0.87)$ for all $D N F$ sites. The seasonal variation of $L E$ is the most robust feature using both daily and monthly ECOR data. In Fig.7 we can also observe a good ability of our $P T$ algorithm to estimate the among-site variability, where the $R^{2}$ of the site-averaged estimated versus observed $L E$ ranges from 0.78 $(p<0.01)$ for all $G R A$ sites to $0.96(p<0.01)$ for all $D N F$ sites and the $R M S E$ varies from $2.1 \mathrm{~W} / \mathrm{m}^{2}$ for all $S H R$ sites to $9.5 \mathrm{~W} / \mathrm{m}^{2}$ for all $S A W$ sites. Overall, the estimated $L E$ based on our algorithm displays a high accuracy according to the validation of seasonal and spatial variation in $L E$. Clearly, our algorithm is also satisfactory in reproducing the inter-annual variability at the site scale for each $P F T$ with at least 3 years of data (Fig. 7). The $R^{2}$ between the measured and estimated annual $L E$ anomaly is significantly below the confidence level of $p<0.05$ and is between 0.71 for all $E N F$ sites and 0.94 for all $D N F$ sites. The lowest $R M S E$ is $2.1 \mathrm{~W} / \mathrm{m}^{2}$ at all $D N F$ sites due to 
the few samples, while the largest $R M S E$ is $5.8 \mathrm{~W} / \mathrm{m}^{2}$ at all $E B F$ sites due to the missing observed $L E$ data caused by bad weather conditions in tropical ecosystems (Falge et al., 2001).

Fig. 7 HERE

\subsubsection{Comparison with other LE algorithms}

Because point-based validation with ground observation is typically a good method to evaluate algorithm performance (Vinukollu et al., 2011a; 2011b), the estimated daily $L E$ at site scale using our $P T$ algorithm were compared with those for the MOD16 algorithm and the PT-JPL algorithm for each PFT. Table 2 shows the results of comparisons between the estimated $L E$ using the three algorithms versus daily ground-observations from the first group using the second group data to calibrate the coefficients of our $P T$ algorithm. For $C R O$ and GRA sites, the average $R M S E$ of the estimated $L E$ using our algorithm is less than $22 \mathrm{~W} / \mathrm{m}^{2}$, and the average $R^{2}$ is more than $0.75(p<0.01)$, which show better performance than the MOD16 algorithm and the PT-JPL algorithm. For all forests sites, the average RMSE of the estimated $L E$ using our $P T$ algorithm is less than $24 \mathrm{~W} / \mathrm{m}^{2}$ and is lower than for the MOD16 algorithm and the PT-JPL algorithm together with slightly higher $R^{2}$ at the 99\% level of confidence. For the SHR and SAW sites, the average RMSE of the estimated $L E$ using our $P T$ algorithm is much lower and the average $R^{2}$ is more than 0.62 (95\% confidence) when compared with the other two algorithms. Overall, the average RMSE for our $P T$ algorithm decreased by approximately $5 \mathrm{~W} / \mathrm{m}^{2}$ for forests and $S H R$ sites, and approximately $3 \mathrm{~W} / \mathrm{m}^{2}$ for $C R O$ and $S A W$ sites, and approximately 
$2 \mathrm{~W} / \mathrm{m}^{2}$ for $G R A$ sites. The average $R^{2}$ increases by approximately $0.1(p<0.05)$ at $S A W$ and $C R O$ sites and, by approximately $0.06(p<0.05)$ at most forest, $S H R$ and GRA sites. This improvement over MOD16 and PT-JPL is expected given our calibration to ECOR data, with which we also used for validation.

Table 2 HERE

Table 3 HERE

Fig. 8 shows a time series for 8-day average $L E$ measurements and tower-driven predictions for PFTs. In comparison to the MOD16 algorithm and the PT-JPL algorithm, in this study our $P T$ algorithm yielded seasonal $L E$ variations that are closest to the ground-measured values. Table 3 presents the statistics of the comparisons of the three $L E$ algorithms from the second group, using the first group data to calibrate the coefficients of our algorithm, and we draw the similar conclusion that our proposed $L E$ algorithm presents better performance for quantifying the turbulent heat fluxes than that of the MOD16 algorithm and the PT-JPL algorithm. Therefore, our $P T$ algorithm is among those algorithms that provide a better fit to flux tower observations.

Fig. 8 HERE

\subsection{Global implementation of the terrestrial LE estimation based on MERRA data}

Based on Eq. (11) parameterized by the coefficients listed in Table 1, we estimated global terrestrial $L E$ during 2000-2009 with a spatial resolution of $0.05^{\circ}$ using MERRA meteorological data and MODIS products. Unfortunately, we found 
that our $P T$ algorithm tends to underestimate $L E$ using MERRA data when compared to ground-measured $L E$ due to the underestimated $R_{n}$ from MERRA data (Fig. 9). To improve the accuracy of the estimated $L E$ driven by MERRA data, we recalibrated the coefficients of Eq. (11) using the MERRA meteorological data, MODIS products and ground-measured $L E$ collected at global-distributed flux tower sites. Table 4 lists the parameters of Eq. (11) for nine different biomes by linear regression based on the MODIS-derived NDVI, ground-measured $f(e), M E R R A$-derived $T_{a}, R H$ and VPD. Cross-validations show that when using MERRA data as a substitute for tower-specific meteorology, our revised $P T$ algorithm driven by MERRA data produced higher predictive errors at most flux towers due to the large errors of MERRA meteorological data. The average $R M S E$ of the daily $L E$ increased from $18.2 \mathrm{~W} / \mathrm{m}^{2}$ using the original algorithm driven by specific-tower meteorology to $20.6 \mathrm{~W} / \mathrm{m}^{2}$ using the revised algorithm driven by MERRA data (Fig. 10). The coefficient of determination $\left(R^{2}\right)$ between the daily $L E$ estimates and observations decreased from 0.84 using the original algorithm to 0.70 using the revised version. Predicted relative errors of $L E$ for MERRA-based revised algorithm compared to the original version also slightly increased by $4 \%$ for validating among-sites variability and annual LE anomalies. Wang et al. (2010a) suggested that the relative error of the required $L E$ simulation for analyzing spatiotemporal variation is typically less than $14 \%$ and the accuracy of our revised algorithm driven by $M E R R A$ data meets this requirement.

Table 4 HERE

Fig. 9 HERE 
Fig.10 HERE

We evaluated the global spatial patterns of $f(e)$ and $L E$ averaged from 2003 through 2005 using monthly MERRA gridded data. Tropical rainfall forests in the Amazon regions of South America, Congo basins of Africa and the Southeast Asia and European monsoonal temperate regions had the highest annual $f(e)$. Arid regions and the Arctic had the lowest annual $f(e)$ due to the contribution of low soil moisture and vegetation cover to decreasing $L E$. Global annual $f(e)$ varies from 0.22 in barren lands, 0.42 in $S H R, 0.51$ in $G R A, 0.65$ in $C R O, 0.66$ in $D B F$, to 0.73 in $E B F$ (Fig.11).

Global annual $L E$ is $41.7 \mathrm{~W} / \mathrm{m}^{2}$ over vegetated regions. The highest annual $L E$ is found in the equatorial tropics and monsoonal subtropical regions due to the sufficient soil moisture and higher vegetation cover. Small $L E$ occurs in cold and dry environments due to the lower temperature and precipitation. $E B F$ has the largest average $L E\left(90.9 \mathrm{~W} / \mathrm{m}^{2}\right)$, followed by $S A W\left(70.3 \mathrm{~W} / \mathrm{m}^{2}\right), D B F\left(61.2 \mathrm{~W} / \mathrm{m}^{2}\right), C R O$ $\left(46.2 \mathrm{~W} / \mathrm{m}^{2}\right), M F\left(37.3 \mathrm{~W} / \mathrm{m}^{2}\right), G R A\left(31.9 \mathrm{~W} / \mathrm{m}^{2}\right), \operatorname{ENF}\left(27.5 \mathrm{~W} / \mathrm{m}^{2}\right), \operatorname{SHR}(19.6$ $\mathrm{W} / \mathrm{m}^{2}$ ) and $D N F\left(18.8 \mathrm{~W} / \mathrm{m}^{2}\right)$ (Fig. 12).

Fig. 11 HERE

Fig. 12 HERE

\section{Discussion}

\subsection{Ecophysiological hypothesis for optimization of the PT parameter}

The basis of $P T$ models is the hypothesis that the energy terms coupled with the 
ecophysiological constraints are the main controller of $L E$ and determine the partition of the sensible and latent heat flux (Jarvis \& Mcnaughton, 1986; Priestley \& Taylor, 1972). In the satellite-based $P T$ algorithms, ecophysiological constraints are recognized as the core regulators for downscaling potential $L E$ to actual $L E$. For unsaturated soil and vegetation surfaces where there is limited supply of soil moisture, ecophysiological constraints and $L E$ are affected significantly by available water and canopy structures (Baldocchi \& Xu, 2007; Davies \& Allen, 1973; Jin et al., 2011; Komatsu, 2003). $f(e)$ used in this study includes the variables $(f(\mathrm{sm})$ and $f(v m))$ for characterizing available water and vegetation information, all of which can be fully acquired from satellite data.

Several studies have suggested using satellite-derived soil moisture with a high spatial heterogeneity to parameterize the soil moisture constraint for estimating soil evaporation (Gokmen et al., 2012; Jin et al., 2012; Miralles et al., 2011). However, satellite-derived soil moisture only considers surface soil moisture from approximately the top $2-5 \mathrm{~cm}$ of the soil profile and neglects the moisture deeper within the soil profile (Anderson et al., 2007; Jarvis et al., 1976). In general, soil evaporation stems from the contributions of soil moisture from all of the different layers of the soil profile. In theory, by combining $R H$ and $V P D, f(\mathrm{sm})$ used in this study couples the entire atmosphere boundary layer and soil evaporation to characterize the atmospheric evaporative demand and hydrological effects on soil moisture diffusion through different soil layers, even though $f(\mathrm{sm})$ may not explicitly represent the soil water deficit on daily scales when convection is frequent and strong 
due to strong vertical mixing (Fisher et al., 2008; Salvucci \& Gentine, 2013). Previous studies have used $f(\mathrm{sm})$ to calculate soil water deficit and neglected their differences in different biomes (Fisher et al., 2008; Mu et al., 2011). However, our algorithm accounts for their differences using $f(\mathrm{sm})$ multiplied with different coefficients. $V P D$-based algorithm maintains a physically realistic representation of soil evaporation and is operational to replace soil moisture-based methods, especially when soil moisture is not available.

In this study, the nonlinear algorithm of $f(\mathrm{vm})$, defined as a function of $N D V I$ and $V P D$, represents an improvement for optimizing $P T$ parameter because it expresses the canopy-level transpiration rate by coupling vegetation water supply with atmospheric evaporative demand. The decrease of $N D V I$ and $L A I$ respond to the rise in vegetation water stress and stomatal closure by altering their leaf density to adapt to the changing environment (Field et al., 1995; Gokmen et al., 2012). NDVI was chosen to substitute $L A I$ because $L A I$ will overestimate vegetation canopy conductance when LAI is higher than 3 (Glenn et al., 2007; Suyker \& Verma, 2008).The $\left(e_{1} N D V I-e_{2}\right) V P D$ term considers the effect of causing $f(e)$ for different biomes to level off in tropic regions with low VPD and highly saturated NDVI values. Although $f(e)$ or $E F$ are more linearly related to NDVI (Choudhury et al., 1994; Wang et al., 2007), our satellite-based hybrid algorithm to determine the $P T$ parameter yields comparable results.

\subsection{Algorithm performance analysis}

Algorithm calibration and validation at 240 globally distributed ECOR flux 
tower sites illustrates that the satellite-based hybrid algorithm for estimating $f(e)$ and $L E$ was reliable and robust across multiple biomes and different climate regions. Fig.6 and Fig.7 demonstrate that the satellite-based hybrid algorithm yielded small errors of $f(e)$ and $L E$ across multiple biomes based on the cross-validations. However, the hybrid algorithm still has relatively low $R^{2}$ and large RMSEs for the estimated $f(e)$ and $L E$ compared to ground-measured data at some irrigated crop sites. This suggests that irrigation and fertilization practices, and in general differences among crop types, may be more critical than canopy structure in determining $P T$ model performance (Zhang et al., 2012). When excluding the observations of these irrigated crop sites, the hybrid algorithm performance greatly improved.

Under the same meteorological and ecological conditions, the hybrid algorithm and $P T$ model had large inter-biome differences for predictive $f(e)$ and $L E$. For instance, the hybrid algorithm yielded the high $f(e)$ values (more than 0.75 under ideal conditions) and explained more than $80 \%$ of the $f(e)$ variability for $G R A$, non-irrigated crop, $D N F$ and $D B F$ sites (Fig.13). Many studies have demonstrated that these PFTs present strong seasonal changes in vegetation leaf, chlorophyll content and red reflectance (Mu et al., 2007; Yebra et al., 2013; Yan et al., 2012; Yao et al., 2014a, 2014b). Satellite-based NDVI responds strongly to variations in red reflectance, chlorophyll and $L A I$ variations as vegetation leaf dries in many vegetation species. Our hybrid algorithm captures this seasonal cycle of vegetation to improve the accuracy of estimating $f(e)$ and $L E$ by using $N D V I$ to parameterize $f(v m)$. In contrast, the hybrid algorithm yielded the poor performances for $f(e) \quad\left(R M S E \geqslant 0.09, R^{2}<0.65\right)$ 
and $L E\left(R M S E \geqslant 17.5 \mathrm{~W} / \mathrm{m}^{2}\right.$ and $\left.R^{2}<0.80\right)$ estimates for site-specific meteorology inputs for $E N F$ and $E B F$ sites. For tall $E N F$ and $E B F$ regions, vegetation seasonal variations are less evident, and NDVI saturates and is contaminated by clouds, which reduces the ability of $f(e)$ to reliably capture satellite signals of vegetation transpiration (Huete et al., 2002). This hypothesis is supported by the previous study of Eugster et al. (2000), which reported that evergreen conifer forests have a canopy conductance that is half that of deciduous forests, which is consistent with our finding that our hybrid method yielded the lowest $f(e)$ for evergreen forests under the same meteorological and eco-physiological conditions (Fig. 13). Direct evidence of this interpretation is that the availability of $f(\mathrm{sm})$ to resolve changes in $f(e)$ and $L E$ in this land functional type is limited, with an $R^{2}$ of $0.34(p<0.05)$ due to the lower bare soil exposure ratio caused by greater overlapping of leaves of different species competing for sunlight (Eugster et al., 2000).

\section{Fig.13 HERE}

A typical difference between our $P T$ algorithm and other two algorithms (PT-JPL and MOD16) is that our algorithm combines ground-observations and physically based ecophysiological constraints to parameterize $f(e)$ for each PFT. Although our algorithm uses a relatively simple and largely empirical equation of the $L E$ process, it has lower uncertainties in the required forcing data and illustrates the improved performance compared to other two algorithms. Moreover, a resistance-based $P M$ algorithm is not accurate to calculate canopy resistance in diverse vegetation, and the structure of the PT-JPL algorithm by design ignores 
classifications among PFTs (Ershadi et al., 2014; Fisher et al., 2009).

The accuracy of our algorithm is highly dependent on the accuracy of the ECOR $L E$ ground-measurements, algorithm inputs errors (including PFT classification map), spatial scale mismatches among different datasets and algorithm inherent limitations. Although ECOR measurements are relatively accurate, they have an error of approximately 5-20\% (Foken, 2008; Glenn et al., 2008) and the gap filling from days to months also leads to $5 \%$ errors for annual values of $L E$ (Hui et al., 2004). Additionally, ECOR measurements have an energy imbalance problem, with $H+L E<R_{n}-G$ (Wilson et al., 2002), and the annual mean energy balance closure at more than 200 FLUXNET sites was approximately 0.8 (Beer et al., 2010). Although several reasons for this energy closure problem have been documented by a substantial body of literature (Foken, 2008; Twine et al., 2000; Wang and Dickinson, 2012) and we corrected it in this study, the errors produced by the correction and measurements are still unclear (Shuttleworth, 2007). Moreover, the biases of other ground-measured meteorological variables $\left(e . g ., T_{a}, R H\right)$ also introduced point-based $f(e)$ and $L E$ estimation errors. When global terrestrial $L E$ was calculated, driven by the MERRA reanalysis dataset, the biases of the MERRA data influenced the accuracy of our algorithm, even though we performed a recalibrated using Eq (11). Recent studies have revealed substantial errors for MERRA data when compared to ground measurements (Zhao et al., 2006; Rienecker., 2011). In this study, we also found that MERRA data usually underestimated $R_{n}$ at high values compared to the ground-measurements (Fig. 9). Our algorithm show significant differences in $L E$ 
estimation if the classification shifts or is wrong. Previous studies revealed that the accuracy of the IGBP layer of the MODIS Collection 5 Land Cover Type product (MCD12Q1) is estimated to be $74.8 \%$ globally (Bartholome and Belward, 2005; Friedl, et al. 2002; Hansen, et al. 2000). Thus, misclassification of the MODIS land cover product will also lead to the use of incorrect parameters in Eq.(11), resulting in less accurate $L E$ estimates.

Typically, the footprints of the ECOR measurements are approximately several hundred meters (Baldocchi, 2008), and the resolutions of both MODIS NDVI $(1 \mathrm{~km}$ and 0.05 degree) and MERRA gridded data $(1 / 2 * 2 / 3$ degree) are greater than the footprints of the ECOR measurements (Rienecker., 2011). The MODIS NDVI and MERRA gridded meteorological data may not adequately capture vegetation and eco-physiological signals at the flux tower sites (Mu et al., 2011; Zhang et al., 2010a). Inaccurate representations of the field measurement footprint may result in algorithm errors for many flux tower sites. The structure of our algorithm will also reduce the accuracy of $L E$ estimates because it ignores the effects of $\mathrm{CO}_{2}$ and WS. High- $\mathrm{CO}_{2}$-induced partial stomatal closure causes an underestimation of daily $L E$ when NDVI tends to increase (Idso and Brazel, 1984; Yao et al., 2013). Our algorithm excludes WS because WS is not globally observable. By quantifying the sensitivity of wind speed to evaporative demand, a recent study revealed that WS contributed substantially to declining evaporation rates (McVicar et al., 2012). For less than two decades, the effect of WS on $L E$ may be negligible, but for several decades, this effect should be considered. 


\subsection{Global terrestrial LE estimation}

Despite the existing errors, our proposed algorithm demonstrated its reliability for calculating annual $L E$, which was compared with other reanalysis, satellite and hydrological datasets. We estimated that the annual global terrestrial $L E$ (excluding Greenland and Antarctica) was $41.7 \mathrm{~W} / \mathrm{m}^{2}$ during 2003-2005, which is slight larger than the value of independent global estimates: $35.3 \mathrm{~W} / \mathrm{m}^{2}$ from a $M O D I S$ product (Mu et al., 2011), $34.2 \mathrm{~W} / \mathrm{m}^{2}$ from GSWP data (Dirmeyer et al., 2006) and 40.2W/m² based on the Atmospheric Water Balance $(A W B)$ method (Mueller et al., 2011). However, recent studies have demonstrated that the global average $L E$ derived from multiple algorithms varies from $34.1 \mathrm{~W} / \mathrm{m}^{2}$ to $42.7 \mathrm{~W} / \mathrm{m}^{2}$, with an average of $36.9 \mathrm{~W} / \mathrm{m}^{2}$ (Wang and Dickinson, 2012). Our estimated annual $L E$ falls within the above range.

The global magnitude of $L E$ for each $P F T$ agreed, in general, with results documented in the literature (Giambelluca et al. 2009; Mu et al., 2011; Zhang et al., 2009, 2010a). We found that $E B F, S A W, D B F$ and $C R O$ have the largest annual average $L E$, greater than $45 \mathrm{~W} / \mathrm{m}^{2}$, and both $S H R$ and $D N F$ have the lowest annual average $L E$, less than $20 \mathrm{~W} / \mathrm{m}^{2}$, which are in good agreement in its representation of AVHRR-LE (Zhang et al., 2010) and MODIS-LE (Mu et al., 2011). Fig. 14 shows the MODIS LE product and our estimates aggregated for vegetation types. In addition, Frank and Inouye (1994) estimated annual LE at 94 sites covering 11 biomes based on approximately 20 years of meteorological records and found that the value of annual $L E$ was approximately $15.7 \mathrm{~W} / \mathrm{m}^{2}$ for tundra, $29.6 \mathrm{~W} / \mathrm{m}^{2}$ for taiga, $45.7 \mathrm{~W} / \mathrm{m}^{2}$ for broadleaf forests, $68.8 \mathrm{~W} / \mathrm{m}^{2}$ for savannas and $106.1 \mathrm{~W} / \mathrm{m}^{2}$ for wet tropical forests. 
Giambelluca et al. (2009) used ECOR observations to document that the annual averaged $L E$ is $64.1 \mathrm{~W} / \mathrm{m}^{2}$ and $53.6 \mathrm{~W} / \mathrm{m}^{2}$ for two tropical savanna sites in Brazil. These comparable results demonstrate the applicability of our algorithm to accurately estimate global terrestrial $L E$.

\section{Fig. 14 HERE}

\section{Conclusions}

We developed a satellite-based hybrid algorithm to calibrated to ECOR measurements to determine the $P T$ parameter for global terrestrial $L E$ estimation across multiple biomes by combining a simple empirical equation with physically based ecophysiological constraints to obtain the sum of the weighted ecophysiological constraints $(f(e))$ from global eddy covariance, satellite and meteorological observations. $f(e)$ considers the differences in coefficients among PFTs and it includes $V P D$-based soil moisture and NDVI-based vegetation factors. The parameters of the hybrid algorithm for nine different biomes are acquired by linear regression based on the satellite-based $N D V I$, ground-measured $L E, T_{a}, R H$, and $V P D$. It has a low sensitivity to errors in the input data.

A series of cross-validations based on 240 global ECOR observations show that the optimization at a PFT level performed well. The satellite-based hybrid algorithm had the highest performance, with an RMSE of 0.07 and an $R^{2}$ of $0.86(p<0.01)$ at $D N F$ sites, and the worst performances, with an $R^{2}$ of $0.55(p<0.01)$, occurred at $E N F$ sites. Cross-validations were also performed to evaluate the ability of our PT method to yield $L E$ seasonal, spatial, and inter-annual variability. On average, the $R M S E$ of 
the estimated monthly (daily) $L E$ varies from $4.3(11.5) \mathrm{W} / \mathrm{m}^{2}$ for all $D N F$ sites to $18.1(20.9) \mathrm{W} / \mathrm{m}^{2}$ for all $C R O$ sites, and the $R^{2}$ (99\% confidence) varies from 0.80 (0.68) for all $S H R$ sites to $0.96(0.87)$ for all $D N F$ sites. Performance was also good for predicting among-site variability, with an $R^{2}$ of more than 0.78 . The validation of inter-annual variability at the site scale shows that the $R^{2}$ between the measured and estimated annual $L E$ anomaly is between 0.71 for all $E N F$ sites and 0.94 for all $D N F$ sites. When compared with the MOD16 and PT-JPL algorithms, which are not calibrated to site measurements unlike our algorithm, our $L E$ algorithm performed better than them at the site scale.

We implemented the terrestrial $L E$ estimation based on MERRA data by recalibrating the coefficients of the satellite-based hybrid algorithm using the MERRA meteorological data, MODIS products and ground-measured LE. The estimated seasonal, spatial, and inter-annual variability of $L E$ agreed well with the tower measurements. Although the predicted relative errors of $L E$ for the MERRA-based revised algorithm compared to the original version increased slightly by $4 \%$ for validating among-site variability and annual $L E$ anomalies, the accuracy of our revised algorithm still met the requirement for analyzing global terrestrial $L E$ changes. The annual average global terrestrial $L E$ for 2003-2005 as estimated by our algorithm driven by MERRA data was approximately $41.7 \mathrm{~W} / \mathrm{m}^{2}$, which is in good agreement with other studies. Our estimates provide information for comparing and calibrating climate and hydrological models in terms of their sensitivity to energy partition.

\section{Acknowledgements}


We would like to thank Prof. Shaomin Liu, Dr. Xiaotong Zhang, Dr. Xiang Zhao, Dr. Xianhong Xie, Dr. Ziwei Xu and Ms. Meng Liu from Beijing Normal University, China, and Prof. Guangsheng Zhou from the Institute of Botany, CAS, and Dr. Yan Li and Dr. Ran Liu from Xinjiang Institute of Ecology and Geography, CAS, and Prof. Guoyi Zhou and Dr. Yuelin Li from South China Botanic Garden, CAS, and Prof. Bin Zhao from Fudan University, China, for providing ground-measured data. This work used eddy covariance data acquired by the FLUXNET community and in particular by the following networks: AmeriFlux (U.S. Department of Energy, Biological and Environmental Research, Terrestrial Carbon Program (DE-FG02-04ER63917 and DE-FG02-04ER63911)), AfriFlux, AsiaFlux, CarboAfrica, CarboEuropeIP, CarboItaly, CarboMont,ChinaFlux, Fluxnet-Canada (supported by CFCAS, NSERC, BIOCAP, Environment Canada, and NRCan), GreenGrass, KoFlux, LBA, NECC, OzFlux, TCOS-Siberia, USCCC. We acknowledge the financial support to the eddy covariance data harmonization provided by CarboEuropeIP, FAO-GTOS-TCO, iLEAPS, Max Planck Institute for Biogeochemistry, National Science Foundation, University of Tuscia, Université Laval, Environment Canada and US Department of Energy and the database development and technical support from Berkeley Water Center, Lawrence Berkeley National Laboratory, Microsoft Research eScience, Oak Ridge National Laboratory, University of California -Berkeley and the University of Virginia. Other ground-measured data were obtained from the GAME AAN (http://aan.suiri.tsukuba.ac.jp/), the Coordinated Enhanced Observation Project $(C E O P)$ in arid and semi-arid regions of northern China (http://observation.tea.ac.cn/), 
and the water experiments of Environmental and Ecological Science Data Center for West China (http:// westdc.westgis.ac.cn/water). MODIS LAI/FPAR, NDVI, Albedo and land cover satellite products were obtained online (http://reverb.echo.nasa.gov/ reverb).This work was partially supported by the High-Tech Research and Development Program of China (No.2013AA122801), the Natural Science Fund of China (No. 41201331, No. 41331173 and No. 41205104). J.B.F. contributed to this paper from the Jet Propulsion Laboratory, California Institute of Technology, under a contract with the National Aeronautics and Space Administration.

\section{References:}

Allen, R., Tasumi, M., \& Trezza, R. (2007). Satellite-based energy balance for mapping evapotranspiration with internalized calibration (METRIC)-Model. Journal of Irrigation and Drainage Engineering, 133, 380-394.

Anderson, M., Norman, M., Diak, G., Kustas, W., \& Mecikalski, J. (1997). A two-source time-integrated model for estimating surface fluxes using thermal infrared remote sensing, Remote Sensing of Environment, 60, 195-216.

Anderson, M., Norman, J., Mecikalski, J., Otkin, J., \& Kustas, W. (2007). A climatological study of evapotranspiration and moisture stress across the continental United States based on thermal remote sensing: 1. model formulation. Journal of Geophysical Research, Atmospheres, 112, D10117.

Baldocchi, D., Falge, E., Gu, L., Olson, R., ollinger, D., Running, S., et al. (2001). FLUXNET: a new tool to study the temporal and spatial variability of ecosystem-scale carbon dioxide, water vapor and energy flux densities. Bulletin 
of the American Meteorological Society, 82, 2415-2434.

Baldocchi, D., \& Xu, L. (2007). What limits evaporation from Mediterranean oak woodlands-The supply of moisture in the soil, physiological control by plants or the demand by the atmosphere? Advances in Water Resources, 30, 2113-2122.

Baldocchi, D. (2008). Breathing of the terrestrial biosphere: Lessons learned from a global network of carbon dioxide flux measurement systems. Australian Journal of Botany, 56, 1-26.

Bastiaanssen, W., Menenti, M., Feddes, R., \& Holtslag, A. (1998). A remote sensing surface energy balance algorithm for land (SEBAL): 1. Formulation. Journal of Hydrology, 212-213, 198-212.

Brutsaert, W., \& Chen, D. (1995). Desorption and the two stages of drying of natural tall grass prairie. Water Resources Research, 31, 1305-1313.

Beer, C., Reichstein, M., Tomelleri, E., Ciais, P., Jung, M., Carvalhais, N., et al., (2010). Terrestrial gross carbon dioxide uptake: Global distribution and covariation with climate. Science, 329, 834-838.

Betts, A., Desjardins, R., \& Worth, D. (2007). Impact of agriculture, forest and cloud feedback on the surface energy budget in BOREAS. Agricultural Forest Meteorology, 142, 156-169.

Bouchet, R. (1963). Evapotranspiration re'elle evapotranspiration potentielle, signification climatique. International Association of Hydrological Sciences, 134-142.

Bartholome, E., \& Belward, A. (2005). GLC2000: a new approach to global land 
cover mapping from Earth observation data. International Journal of Remote Sensing, 6, 1959-1977.

Carlson, T. (2007). An overview of the "triangle method" for estimating surface evapotranspiration and soil moisture from satellite imagery. Sensors, 7, $1612-1629$.

Choudhury, B. J., Ahmed, N. U., Idso, S. B., Reginato, R. J., \& Daughtry, C. S. T. (1994). Relations between evaporation coefficients and vegetation indexes studied by model simulations. Remote Sensing of Environment, 50, 1-17.

Chen, Y., Xia, J., Liang, S., Feng, J., Fisher, J.B., Li, X., et al. (2014).Comparison of satellite-based evapotranspiration models over terrestrial ecosystems in China. Remote Sensing of Environment, 140, 279-293.

Cleugh, H., Leuning, R., Mu, Q., \& Running, S. (2007). Regional evaporation estimates from flux tower and MODIS satellite data. Remote Sensing of Environment, 106, 285-304.

Davies, J., \& Allen, C. (1973). Equilibrium, potential and actual evaporation from cropped surface in southern Ontario. Journal of Applied Meteorology, 12, 649-657.

Detto, M., Montaldo,N., Albertson, J., Mancini, M., \& Katul, G. (2006). Soil moisture and vegetation controls on evapotranspiration in a heterogeneous Mediterranean ecosystem on Sardinia, Italy. Water Resources Research, 42, W08419.

Dirmeyer, P. A., Gao, X., Zhao, M., Guo, Z., Oki, T., \& Hanasaki, N. (2006). 
GSWP-2: Multimodel analysis and implications for our perception of the land surface. Bulletin of the American Meteorological Society, 87, 1381-1397.

Ershadi, A., McCabe, M., Evans, J., Chaney, N., \& Wood, E. (2014). Multi-site evaluation of terrestrial evaporation models using FLUXNET data. Agricultural Forest Meteorology,187, 46-61.

Eugster, W., Rouse, W., Pielke Sr, R., Mcfadden, J., Baldocchi, D., F Kittel, T., et al., (2000). Land-atmosphere energy exchange in Arctic tundra and boreal forest: Available data and feedbacks to climate. Global Change Biology, 6, 84-115.

Falge, E., Baldocchi, D., Olson, R., Anthoni, P., Aubinet, M., Bernhofer, C., et al., (2001). Gap filling strategies for long term energy flux data sets. Agricultural and Forest Meteorology, 107, 71-77.

Federer, C. A., Vörösmarty, C. J., \& Fekete, B. (1996). Intercomparison of methods for calculating potential evaporation in regional and global water balance models. Water Resources Research, 32, 2315-2321.

Field, C.B., Randerson, J.T., \& Malmstrom, C.M. (1995).Global net primary production-Combining ecology and remote-sensing. Remote Sensing of Environment, 51, 74-88.

Fisher, J.B., Tu, K.P., \& Baldocchi, D. D. (2008). Global estimates of the land atmosphere water flux based on monthly AVHRR and ISLSCP-II data, validated at 16 FLUXNET sites. Remote Sensing of Environment, 112, 901-919.

Fisher, J.B., Malhi, Y., Bonal, D., Da Rocha, H., De Araújo, A., Gamo, M., et al. (2009). The land-atmosphere water flux in the tropics. Global Change Biology, 
$15,2694-2714$.

Foken, T. (2008). The energy balance closure problem: An overview. Ecological Applications, 18, 1351-1367.

Frank, D. A., \& Inouye, R. S. (1994). Temporal variation in actual evapotranspiration of terrestrial ecosystems-Patterns and ecological implications. Journal of Biogeography, 21, 401-411.

Friedl, M., McIver, D., Hodges, J., Zhang, X., Muchoney, D., Strahler, A., et al., (2002). Global land cover mapping from MODIS: Algorithms and early results. Remote Sensing of Environment, 83, 287-302.

Gao, X., \& Dirmeyer, P. (2006). A multimodel analysis, validation, and transferability study of global soil wetness products. Journal of Hydrometeorology, 7, 1218-1236.

Giambelluca, T. W., Scholz, F. G., Bucci, S. J., Meinzer, F. C., Goldstein, G., Hoffmann, W. A., et al., (2009). Evapotranspiration and energy balance of Brazilian savannas with contrasting tree density. Agricultural Forest Meteorology, 149, 1365-1376.

Glenn, E. P., Huete, A. R., Nagler, P. L., Hirschboeck, K. K., \& Brown, P. (2007). Integrating remote sensing and ground methods to estimate evapotranspiration. Critical Reviews in Plant Sciences, 26, 139-168.

Glenn, E. P., Morino, K., Didan, K., Jordan, F., Carroll, K. C., Nagler, P. L., et al. (2008b). Scaling sap flux measurements of grazed and ungrazed shrub communities with fine and coarse-resolution remote sensing. Ecohydrology, 1, 
316-329.

Global Modeling and Assimilation Office (2004). File specification for GEOSDAS gridded output version 5.3, report. Greenbelt, Md: NASA Goddard Space Flight Cent.

Gokmen, M., Vekerdy, Z., Verhoef, A., Verhoef, W., Batelaan, O., \& van der Tol, C. (2012). Integration of soil moisture in SEBS for improving evapotranspiration estimation under water stress conditions. Remote Sensing of Environment, 121, 261-274.

Gowda, P., Chavez, J., Colaizzi, P., Evett, S., Howell, T., \& Tolk, J. (2008). ET mapping for agricultural water management: present status and challenges. Irrigation Science, 26, 223-237.

Hansen, M., Defries, R., Townshend, J., \& Sohlberg, R. (2000).Global land cover classification at $1 \mathrm{~km}$ spatial resolution using a classification tree approach. International Journal of Remote Sensing, 21, 1331-1364.

Halliwell, D., \& Rouse, W. (1987). Soil heat flux in permafrost: characteristics and accuracy of measurement. Journal of Climate, 7, 571-584.

Huete, A., Didan, K., Miura, T., Rodriguez, E., Gao, X., \& Ferreira, L. (2002). Overview of the radiometric and biophysical performance of the MODIS vegetation indices. Remote Sensing of Environment, 83, 195-213.

Hui, D., Wan, S., Su, B., Katul, G., Monson, R., \& Luo,Y. (2004). Gap-filling missing data in eddy covariance measurements using multiple imputation (MI) for annual estimations. Agricultural Forest Meteorology, 121, 93-111. 
Idso, S.B., \& Brazel, A.J. (1984). Rising atmospheric carbon dioxide concentrations may increase stream flow. Nature, 312, 51-53.

Jackson, R., Reginato, R., \& Idso, S. (1977). Wheat canopy temperature: a practical tool for evaluating water requirements. Water Resources Research, 13, 651-656.

Jarvis, P., \& Mcnaughton, K. (1986). Stomatal control of transpiration-Scaling up from leaf to region. Advances in Ecological Research, 15, 1-49.

Jarvis, P. (1976). The interpretation of the variations in leaf water potential and stomatal conductance found in canopies in the field. Philosophical Transactions of the Royal Society B: Biological Sciences, 273, 593-610.

Jia, K., Liang, S., Liu, Q., Xiao, Z., Li, Y., Yao, Y., et al. (2014). Global land surface fractional vegetation cover estimation using general regression neural networks from MODIS surface reflectance. IEEE Transactions on Geoscience and Remote Sensing, doi: 10.1109/TGRS.2015.2409563.

Jiang, L., \& Islam, S. (2001). Estimation of surface evaporation map over Southern Great Plains using remote sensing data. Water Resources Research, 37, 329-340.

Jiménez, C., Prigent, C., Mueller, B., Seneviratne, S., McCabe, M., Wood, E., et al. (2011). Global intercomparison of 12 land surface heat flux estimates. Journal of Geophysical Research, Atmospheres, 116, D02102.

Jin, Y., Randerson,J., \& Goulden, M. (2011). Continental-scale net radiation and evapotranspiration estimated using MODIS satellite observations. Remote Sensing of Environment, 115, 2302-2319.

Jung, M., Reichstein, M., Ciais, P., Seneviratne, S.I., Sheffield, J., Goulden, M.L., et 
al. (2010). Recent decline in the global land evapotranspiration trend due to limited moisture supply. Nature, 467, 951-954.

Jung, M., Reichstein, M., Margolis, H., Cescatti, A., Richardson, A., Altaf Arain, M., et al. (2011). Global patterns of land-atmosphere fluxes of carbon dioxide, latent heat, and sensible heat derived from eddy covariance, satellite, and meteorological observations. Journal of Geophysical Research, Atmospheres, 116, G00J07.

Kalma, J., McVicar, T., \& McCabe, M. (2008). Estimating Land Surface Evaporation: A Review of Methods Using Remotely Sensed Surface Temperature Data accomplished. Surveys in Geophysics, 29, 421-469.

Komatsu, T. (2003). Toward a robust phenomenological expression of evaporation efficiency for unsaturated soil surface. Journal of Applied Meteorology, 42, $1330-1334$.

Kustas, W., \& Daughtry, C. (1990). Estimation of the soil heat-flux net-radiation ratio from spectral data. Agricultural Forest Meteorology, 49, 205-223.

Kustas, W., \& Norman, M. (1996). Use of remote sensing for evapotranspiration monitoring over land surfaces. Hydrological Sciences Journal, 41, 495-516.

Leuning, R. (1995). A critical appraisal of a combined stomatal-photosynthesis model for C3 plants. Plant, Cell and Environment, 18, 339-355.

Liang, S., Li, X., \& Wang, J. (Eds.) (2012). Advanced remote sensing: Terrestrial information extraction and applications: Academic Press.

Liang, S., Wang, K., Zhang, X., \& Wild, M. (2010). Review on estimation of land 
surface radiation and energy budgets from ground measurement, remote sensing and model simulations. IEEE Journal of Selected Topics in Applied Earth Observations and Remote Sensing, 3, 225-240.

Liu, S., Xu, Z., Wang, W., Jia, Z., Zhu, M., Bai, J., et al. (2011). A comparison of eddy-covariance and large aperture scintillometer measurements with respect to the energy balance closure problem. Hydrology and Earth System Sciences, 15, 1291-1306.

Liu, S., Xu, Z., Zhu, Z., Jia, Z., \& Zhu M. (2013). Measurements of evapotranspiration from eddy-covariance systems and large aperture scintillometers in the Hai River Basin, China. Journal of Hydrology, 487, 24-38.

Los, S., Collatz, G., Sellers, P., Malmström, C., Pollack, N., DeFries, R., et al. (2000). A global 9-yr biophysical land surface dataset from NOAA AVHRR data. Journal of Hydrometeorology, 1, 183-199.

Lu, X., \& Zhuang, Q. (2010). Evaluating evapotranspiration and water-use efficiency of terrestrial ecosystems in the conterminous United States using MODIS and AmeriFlux data. Remote Sensing of Environment, 114, 1924-1939.

Margolis, H., \& Ryan, M. (1997). A physiological basis for biosphere-atmosphere interactions in the boreal forest: An overview. Tree Physiology, 17, 491-499.

McVicar, T., Roderick, M., Donohue, R., Li, L., Van Niel, T., Thomas, A., et al., (2012). Global review and synthesis of trends in observed terrestrial near-surface wind speeds: Implications for evaporation. Journal of Hydrology, 416-417,182-205. 
Miralles, D., Holmes, T., De Jeu, R., Gash, J., Meesters, A., \& Dolman, A. (2011). Global land-surface evaporation estimated from satellite-based observations. Hydrology and Earth System Sciences, 15, 453-469.

Misson, L., Panek, J., \& Goldstein, A. (2004). A comparison of three approaches to modeling leaf gas exchange in annually drought-stressed Ponderosa pine forests. Tree Physiology, 24, 529-541.

Monteith, J. (1965). Evaporation and environment. Symposia of the Society for Experimental Biology, 19, 205- 224.

Mueller, B., Seneviratne, S., Jiménez, C., Corti, T., Hirschi, M., Balsamo, G., et al. (2011). Evaluation of global observations-based evapotranspiration datasets and IPCC AR4 simulations. Geophysical Research Letters, 38, L06402.

Mu, Q., Heinsch, F., Zhao, M., \& Running, S. (2007). Development of a global evapotranspiration algorithm based on MODIS and global meteorology data, Remote Sensing of Environment, 111, 519-536.

Mu, Q., Zhao, M., \& Running, S. (2011). Improvements to a MODIS global terrestrial evapotranspiration algorithm. Remote Sensing of Environment, 115, 1781-1800.

Norman, J., Kustas, W., \& Humes, K. (1995). Source approach for estimating soil and vegetation energy fluxes in observations of directional radiometric surface temperature. Agricultural Forest Meteorology, 77, 263-293.

Price, J. (1990) Using spatial context in satellite data to infer regional scale evapotranspiration. IEEE Transactions on Geoscience and Remote Sensing, 28, 940-948.

Priestley, C., \& Taylor, R. (1972). On the assessment of surface heat flux and evaporation using large-scale parameters. Monthly Weather Review, 100, 81-92. 
Reichstein, M., Falge, E., Baldocchi, D., Papale, D., Valentini, R., Aubinet, M., et al., (2005). On the separation of net ecosystem exchange into assimilation and ecosystem respiration: review and improved algorithm. Global Change Biology, $11,1424-1439$.

Rienecker, M., Suarez, M., Gelaro, R., Todling, R., Bacmeister, J., Liu, E., et al., (2011). MERRA-NASA's Modern-Era Retrospective Analysis for Research and Applications. Journal of Climate, 24, 3624-3648.

Rouse, W., (1984). Microclimate at arctic tree line. The effects of regional advection on the surface energy balance of upland tundra. Water Resources Research, 20, 74-78.

Salvucci,G., \& Gentine, P. (2013). Emergent relation between surface vapor conductance and relative humidity profiles yields evaporation rates from weather data. Proceedings of the National Academy of Sciences of the United States of America, 110, 6287-6291.

Shuttleworth, W., \& Wallace, J. (1985). Evaporation from sparse crops-An energy combination theory. Quarterly Journal of the Royal Meteorological Society, 111, 839-855.

Shuttleworth, W. J. (2007). Putting the "vap” into evaporation. Hydrology and Earth System Sciences, 11, 210-244.

Stewart, J., Kustus, W., Humes, K., Nichols, W., Moran, M., \& De Bruin, H. (1994). Sensible heat flux-radiometric surface temperature relationship for eight semiarid areas. Journal of Applied Meteorology, 33, 1110-1117. 
Sumner, D., \& Jacobs, J. (2005). Utility of Penman-Monteith, Priestley-Taylor, reference evapotranspiration, and pan evaporation methods to estimate pasture evapotranspiration. Journal of Hydrology, 308, 81-104.

Suyker, A., \& Verma, S. (2008). Interannual water vapor and energy exchange in an irrigated maize-based agroecosystem. Agricultural Forest Meteorology,148, 417-427.

Su, Z. (2002). The Surface Energy Balance System (SEBS) for estimation of turbulent heat fluxes. Hydrology and Earth System Sciences, 6, 85-100.

Tang, R., Li, Z., \& Tang, B. (2010). An application of the Ts-VI triangle method with enhanced edges determination for evapotranspiration estimation from MODIS data in arid and semi-arid regions: Implementation and validation. Remote Sensing of Environment, 114, 540-551.

Tang, R., \& Li, Z. (2015). Evaluation of two end-member-based models for regional land surface evapotranspiration estimation from MODIS data. Agricultural Forest Meteorology,202, 69-82.

Tucker, C. (1979). Red and photographic infrared linear combinations for monitoring vegetation. Remote Sensing of Environment, 8, 127-150.

Twine, T.E., Kustas, W.P., Norman, J.M., Cook, D.R., Houser, P.R., Meyers, T.P., et al. (2000). Correcting eddy-covariance flux underestimates over a grassland. Agricultural Forest Meteorology, 103, 279-300.

Vinukollu, R.K., Meynadier, R., Sheffield, J., \& Wood, E. F. (2011a). Multi-model, multi-sensor estimates of global evapotranspiration: climatology, uncertainties 
and trends. Hydrological Processes, 25, 3993-4010.

Vinukollu, R.K., Wood, E.F., Ferguson, C.R., \& Fisher, J.B. (2011b). Global estimates of evapotranspiration for climate studies using multi-sensor remote sensing data: evaluation of three process-based approaches. Remote Sensing of Environment, 115, 801-823.

Wagner, W., Scipal, K., Pathe, C., Gerten, D., Lucht, W., \& Rudolf, B. (2003). Evaluation of the agreement between the first global remotely sensed soil moisture data with model and precipitation data. Journal of Geophysical Research, Atmospheres, 108(D19), 4611.

Wang, K., \& Dickinson, R. (2012). A review of global terrestrial evapotranspiration: observation, modeling, climatology, and climatic variability. Reviews of Geophysics, 50, RG2005.

Wang, K., Li, Z., \& Cribb, M. (2006). Estimation of evaporative fraction from a combination of day and night land surface temperatures and NDVI: A new method to determine the Priestley-Taylor parameter. Remote Sensing of Environment, 102, 293-305.

Wang, K. \& Liang, S. (2008). An improved method for estimating global evapotranspiration based on satellite determination of surface net radiation, vegetation index, temperature, and soil moisture. Journal of Hydrometeorology, $9,712-727$.

Wang, K., Wang, P., Li, Z., \& Sparrow, M. (2007). A simple method to estimate actual evapotranspiration from a combination of net radiation, vegetation index, and temperature. Journal of Geophysical Research, Atmospheres, 112, D15107. 
Wang, K., Dickinson, R. E.,Wild, M., \& Liang, S. (2010a). Evidence for decadal variation in global terrestrial evapotranspiration between 1982 and 2002: 1.Model development. Journal of Geophysical Research, Atmospheres, 115, D20112.

Wang, K., Dickinson, R. E.,Wild, M., \& Liang, S. (2010b). Evidence for decadal variation in global terrestrial evapotranspiration between 1982 and 2002: 2 . Results. Journal of Geophysical Research, Atmospheres, 115, D20113.

Wilson, K., Goldstein, A., Falge, E., Aubinet, M., Baldocchi, D., Berbigier, P., et al., (2002). Energy balance closure at FLUXNET sites. Agricultural Forest Meteorology, 113, 223-243.

Xu, L., \& Baldocchi, D. (2003). Seasonal trend of photosynthetic parameters and stomatal conductance of blue oak (Quercus douglasii) under prolonged summer drought and high temperature. Tree Physiology, 23, 865-877.

Yang, F., White, M., Michaelis, A., Ichii K., Hashimoto, H., Votava, P., et al. (2006). Prediction of continental-scale evapotranspiration by combining MODIS and AmeriFlux data through support vector machine. IEEE Transactions on Geoscience and Remote Sensing, 44, 3452-3461.

Yan, H., Wang, S., Billesbach, D., Oechel, W., Zhang, J., Meyers, T., et al., (2012). Global estimation of evapotranspiration using a leaf area index-based surface energy and water balance model. Remote Sensing of Environment, 124, 581-595.

Yao, Y., Liang, S., Qin, Q., Wang, K., \& Zhao, S. (2011). Monitoring global land surface drought based on a hybrid evapotranspiration model. International 
Journal of Applied Earth Observation and Geoinformation, 13, 447-457.

Yao, Y., Liang, S., Cheng, J., Liu, S., Fisher, J.B., Zhang, X., et al. (2013). MODIS-driven estimation of terrestrial latent heat flux in China based on a modified Priestley-Taylor algorithm. Agricultural Forest Meteorology, 171-172, 187-202.

Yao, Y., Liang, S., Li, X., Hong, Y., Fisher, J.B., et al., (2014a). Bayesian multimodel estimation of global terrestrial latent heat flux from eddy covariance, meteorological, and satellite observations. Journal of Geophysical Research, Atmospheres, 119, 4521-4545.

Yao, Y., Liang, S., Xie, X., Cheng, J., Jia, K., Li, Y., et al., (2014b). Estimation of the terrestrial water budget over northern China by merging multiple datasets. Journal of Hydrology, 519, 50-68.

Yebra, M., Van Dijk, A., Leuning, R.,, Huete, A., \& Guerschman, J. (2013). Evaluation of optical remote sensing to estimate actual evapotranspiration and canopy conductance. Remote Sensing of Environment, 129, 250-261.

Yuan, W., Liu, S., Yu, G., Bonnefond, J., Chen, J., Davis, K., et al. (2010). Global estimates of evapotranspiration and gross primary production based on MODIS and global meteorology data. Remote Sensing of Environment, 114, 1416-1431.

Zeng, Z., Wang, T., Zhou, F., Ciais, P., Mao, J., Shi, X., et al. (2014). A worldwide analysis of spatiotemporal changes in water balance-based evapotranspiration from 1982 to 2009. Journal of Geophysical Research, Atmospheres, 119, 1186-1202. 
Zhang, F.M., Chen, J.M., Chen, J.Q., Gough, C.M., Martin, T.A., \& Dragoni, D. (2012). Evaluating spatial and temporal patterns of MODIS GPP over the conterminous U.S. against flux measurements and a process model. Remote Sensing of Environment, 124, 717-729.

Zhang, K., Kimball, J.S., Mu, Q., Jones, L., Goetz, S., \& Running, S. (2009). Satellite based analysis of northern ET trends and associated changes in the regional water balance from 1983 to 2005. Journal of Hydrology, 379, 92-110.

Zhang, K., Kimball, J., Nemani, R., \& Running, S. (2010a). A continuous satellite-derived global record of land surface evapotranspiration from 1983 to 2006. Water Resources Research, 46, W09522.

Zhao, M., Heinsch,F., Nemani, R., \& Running, S. (2005). Improvements of the MODIS terrestrial gross and net primary production global data set. Remote Sensing of Environment, 95, 164-176.

Zhao, M., Running, S. W., \& Nemani, R. R. (2006). Sensitivity of Moderate Resolution Imaging Spectroradiometer (MODIS) terrestrial primary production to the accuracy of meteorological reanalysis. Journal of Geophysical Research, Atmospheres, 111, G01002.

Zhang, Y., Leuning, R., Hutley, L., Beringer, J., McHugh, I., \& Walker, J. (2010b). Using long-term water balances to parameterize surface conductances and calculate evaporation at $0.05^{\circ}$ spatial resolution. Water Resources Research, 46, W05512. 
Table 1. Coefficients derived from global plant functional type-based optimization of Eq. (11) using MODIS NDVI and tower-specific meteorology. DBF: deciduous broadleaf forest; DNF: deciduous needleleaf forest; EBF: evergreen broadleaf forest; ENF: evergreen needleleaf forest; MF: mixed forest; SAW: savannas and woody savannas; SHR: open shrubland and closed shrubland; CRO: cropland; GRA: grassland, urban and built-up, barren or sparsely vegetated.

\begin{tabular}{llllll}
\hline Plant & \multicolumn{5}{c}{ Coefficients for different PFTs } \\
\cline { 2 - 6 } $\begin{array}{l}\text { Functional } \\
\text { Types }\end{array}$ & $k_{0}$ & $k_{1}$ & $k_{2}$ & $k_{3}$ & $k_{4}$ \\
\hline CRO & 0.2093 & 0.0024 & 0.5558 & 0.1651 & 0.4860 \\
GRA & 0.2734 & 0.0070 & 0.4556 & 0.2329 & 0.4399 \\
SAW & 0.1749 & 0.0022 & 0.4972 & 0.1573 & 0.4279 \\
SHR & 0.2101 & 0.0061 & 0.3729 & 0.1595 & 0.3102 \\
DNF & -0.2442 & 0.0119 & 0.7722 & 0.1474 & 0.5500 \\
DBF & -0.0456 & 0.0114 & 0.5417 & 0.1510 & 0.4118 \\
MF & 0.4968 & 0.0110 & 0.0724 & 0.7139 & 0.7495 \\
EBF & 0.2740 & 0.0047 & 0.3820 & 0.1170 & 0.2190 \\
ENF & 0.1730 & 0.0091 & 0.3680 & 0.0656 & 0.0765 \\
\hline Average & 0.1691 & 0.0073 & 0.4464 & 0.2122 & 0.4079 \\
\hline
\end{tabular}


Table 2. A summary of the statistics (bias, the Root Mean Square Error, RMSE, and the square of the correlation coefficients, $R^{2}$ ) of the comparison between the ground-measured and the estimated average daily $L E$ using the three LE algorithms driven by tower-specific meteorology of the first group. The second group was used as training data to calibrate the coefficients of our PT algorithm. The bias and RMSE are in units of $\mathrm{W} / \mathrm{m}^{2}$. $P T$-Hybrid stands for our $P T$ algorithm.

\begin{tabular}{llllllllll}
\hline \multirow{2}{*}{ PFTs } & \multicolumn{3}{c}{ Bias } & \multicolumn{3}{c}{ RMSE } & \multicolumn{2}{c}{$R^{2}$} \\
\cline { 2 - 9 } & MOD16 & PT-JPL & PT-Hybrid & MOD16 & PT-JPL & PT-Hybrid & MOD16 & PT-JPL & PT-Hybrid \\
\hline DBF & -10.2 & 9.8 & 5.4 & 28.7 & 27.1 & 21.6 & 0.61 & 0.73 & 0.79 \\
DNF & -9.1 & 5.4 & 3.3 & 21.2 & 19.2 & 12.9 & 0.42 & 0.65 & 0.81 \\
EBF & -6.3 & 18.7 & 2.8 & 27.6 & 34.3 & 23.4 & 0.57 & 0.58 & 0.69 \\
ENF & -5.5 & 13.1 & 2.1 & 30.5 & 31.2 & 22.8 & 0.42 & 0.64 & 0.66 \\
MF & -6.7 & 5.8 & 3.4 & 27.4 & 28.1 & 20.4 & 0.48 & 0.72 & 0.80 \\
SAW & -8.2 & 11.3 & 5.2 & 25.9 & 22.3 & 19.7 & 0.47 & 0.53 & 0.71 \\
SHR & -1.8 & 8.6 & 4.6 & 26.1 & 22.8 & 16.8 & 0.41 & 0.59 & 0.63 \\
CRO & -12.6 & -2.3 & 6.5 & 32.3 & 25.3 & 21.1 & 0.52 & 0.68 & 0.77 \\
GRA & -9.2 & 1.8 & 4.3 & 26.9 & 19.8 & 18.7 & 0.50 & 0.70 & 0.76 \\
\hline Average & -7.7 & 8.0 & 4.2 & 27.4 & 25.6 & 19.7 & 0.50 & 0.64 & 0.74 \\
\hline
\end{tabular}


Table 3. A summary of the statistics (bias, the Root Mean Square Error, RMSE, and the square of the correlation coefficients, $R^{2}$ ) of the comparison between the ground-measured and the estimated average daily $L E$ using the three LE algorithms driven by tower-specific meteorology of the second group. The first group was used as training data to calibrate the coefficients of our PT algorithm. The bias and RMSE are in units of $\mathrm{W} / \mathrm{m}^{2}$. $P T$-Hybrid stands for our $P T$ algorithm.

\begin{tabular}{|c|c|c|c|c|c|c|c|c|c|}
\hline \multirow[t]{2}{*}{ PFTs } & \multicolumn{3}{|l|}{ Bias } & \multicolumn{3}{|c|}{ RMSE } & \multicolumn{3}{|l|}{$R^{2}$} \\
\hline & MOD16 & PT-JPL & PT-Hybrid & MOD16 & PT-JPL & PT-Hybrid & MOD16 & PT-JPL & PT-Hybrid \\
\hline DBF & -12.6 & 6.2 & 4.7 & 33.2 & 30.3 & 24.3 & 0.57 & 0.62 & 0.78 \\
\hline DNF & -7.5 & 9.2 & 7.2 & 26.3 & 27.8 & 19.4 & 0.45 & 0.49 & 0.59 \\
\hline EBF & -12.6 & 14.8 & 1.2 & 37.2 & 39.8 & 31.8 & 0.41 & 0.42 & 0.62 \\
\hline ENF & -5.3 & 7.4 & 2.8 & 28.1 & 23.8 & 20.7 & 0.45 & 0.59 & 0.79 \\
\hline MF & -1.7 & 10.2 & 4.6 & 27.3 & 27.1 & 21.9 & 0.51 & 0.65 & 0.81 \\
\hline SAW & -18.9 & 6.1 & 1.1 & 30.7 & 27.5 & 20.6 & 0.41 & 0.51 & 0.61 \\
\hline SHR & -2.2 & 9.3 & 1.2 & 26.6 & 23.8 & 18.1 & 0.41 & 0.52 & 0.59 \\
\hline CRO & -14.3 & -1.8 & 3.8 & 34.8 & 30.8 & 29.5 & 0.42 & 0.51 & 0.63 \\
\hline GRA & -7.3 & 5.2 & 3.9 & 28.8 & 26.6 & 23.4 & 0.41 & 0.52 & 0.60 \\
\hline Average & -9.1 & 7.4 & 3.4 & 30.3 & 28.6 & 23.3 & 0.45 & 0.54 & 0.67 \\
\hline
\end{tabular}


Table 4. Coefficients derived from global plant functional type-based optimization of Eq. (11) using MODIS NDVI and MERRA meteorological data.

\begin{tabular}{llllll}
\hline PFTs & \multicolumn{5}{c}{ Coefficients for different PFTs } \\
\cline { 2 - 6 } & $k_{0}$ & $k_{1}$ & $k_{2}$ & $k_{3}$ & $k_{4}$ \\
\hline CRO & 0.6695 & 0.0001 & 0.0676 & 0.2626 & 0.4966 \\
GRA & 0.2489 & 0.0039 & 0.3861 & 0.2310 & 0.6695 \\
SAW & 0.0263 & 0.0063 & 0.5900 & 0.1525 & 0.5625 \\
SHR & 0.1475 & 0.0063 & 0.4038 & 0.2400 & 0.6788 \\
DNF & 0.3941 & 0.0033 & 0.0001 & 0.3019 & 0.6172 \\
DBF & 0.5499 & 0.0078 & 0.0078 & 0.5473 & 0.8164 \\
MF & 0.5951 & 0.0081 & 0.0001 & 0.4246 & 0.4721 \\
EBF & 0.4698 & 0.0081 & 0.1053 & 0.1694 & 0.1891 \\
ENF & 0.4663 & 0.0080 & 0.1072 & 0.1642 & 0.2428 \\
\hline Average & 0.3964 & 0.0058 & 0.1853 & 0.2771 & 0.5272 \\
\hline
\end{tabular}




\section{Figure captions}

Fig.1. The spatial distribution of 240 eddy covariance flux tower sites used in this study.

Fig.2.An example of the time series of the 8-day $f(e), T_{a}, f(\mathrm{sm})$ and $f(\mathrm{vm})$ derived from ground-measured data during January 2002-December 2006 at Au-How site. Here. $f(s m)=R H^{V P D}, f(v m)=\left(k_{3} N D V I-k_{4}\right) V P D$. Both $k_{3}$ and $k_{4}$ of Eq.(11) were calibrated using by linear regression using the observed data collected from Au-How site.

Fig.3. Scatter plots of the observed monthly $f(e)$ versus $f(\mathrm{sm})$ at the site scale for each PFT. $f(e)$ is inverted from E.q(3) using ground-measured $R_{n}, L E, T_{a}$ and $G$ collected from flux tower sites. $f(\mathrm{sm})$ is calculated using $R H$ and VPD collected from flux tower sites.

Fig.4. Scatter plots of the observed monthly $f(e)$ versus $f(v m)$ at the site scale for each PFT. $f(e)$ is inverted from E.q(3) using ground-measured $R_{n}, L E, T_{a}$ and $G$ collected from flux tower sites. $f(v m)=\left(k_{3} N D V I-k_{4}\right) V P D$, which is calculated using MODIS NDVI and VPD collected from flux tower sites. Both $k_{3}$ and $k_{4}$ of Eq. (11) were calibrated using by linear regression using the observed data collected flux tower sites.

Fig. 5. Sensitivity of $f(e)$ to variations in the amounts of a) $T_{a}(R H=0.7, N D V I=0.7)$, b) $R H \quad\left(T_{a}=25^{\circ} \mathrm{C}, N D V I=0.7\right)$ and c) $N D V I\left(T_{a}=25^{\circ} \mathrm{C}, R H=0.7\right)$. Other input variables are set as constants when one variable changes.

Fig. 6. Cross-validation of the estimated monthly $f(e)$ using the hybrid algorithm driven by tower-specific Meteorology versus ground-measured $f(e)$ for each PFT.

Fig. 7. The estimated $L E$ ( $y$ axis, unit: $\mathrm{W} / \mathrm{m}^{2}$ ) using our $P T$ algorithm driven by tower-specific Meteorology versus ground-measured $L E$ ( $x$ axis, unit: $\mathrm{W} / \mathrm{m}^{2}$ ) for cross validation for daily $L E$, monthly $L E$, among-sites variability and annual $L E$ anomalies.

Fig. 8. Example of a time series for the 8 day $L E$ average as measured and estimated using three tower-driven algorithms for different PFTs. $y$ axis represents $L E$, unit: 
$\mathrm{W} / \mathrm{m}^{2} ; x$ axis represents time series of year. $P T$-Hybrid stands for our $P T$ algorithm.

Fig.9. An example of a) comparison of daily $L E$ observations at US-Wcr site and the corresponding estimated $L E$ based on Eq. (11) with the coefficients listed in Table 1 driven by the MERRA dataset. b) comparison of daily $R_{n}$ observations at US-Wcr site and the corresponding $R_{n}$ derived from MERRA dataset.

Fig. 10. The estimated $L E$ ( $y$ axis, unit: $\mathrm{W} / \mathrm{m}^{2}$ ) using our $P T$ algorithm driven by MERRA meteorological data versus ground-measured $L E\left(x\right.$ axis, unit: $\left.\mathrm{W} / \mathrm{m}^{2}\right)$ for cross validation for daily $L E$, monthly $L E$, among-sites variability and annual $L E$ anomalies.

Fig.11. Spatial distribution of annual global terrestrial $f(e)$ averaged for 2003-2005 at spatial resolution of $0.05^{\circ}$ according to the satellite-based hybrid algorithm driven by MODIS NDVI and MERRA meteorology.

Fig.12. Spatial distribution of annual global terrestrial LE averaged for 2003-2005 at spatial resolution of $0.05^{\circ}$ according to our PT algorithm driven by MODIS NDVI and MERRA meteorology.

Fig.13. Variability of $f(e)$ at multiple biomes using the same inputs $\left(T_{a}=25^{\circ} \mathrm{C}\right.$, $\mathrm{RH}=0.7$ and $\mathrm{NDVI}=0.7$ ).

Fig.14. Comparison of our LE estimates and MODIS-LE product at the various ecosystem types. $P T$-Hybrid stands for our $P T$ algorithm. 
Figure 1

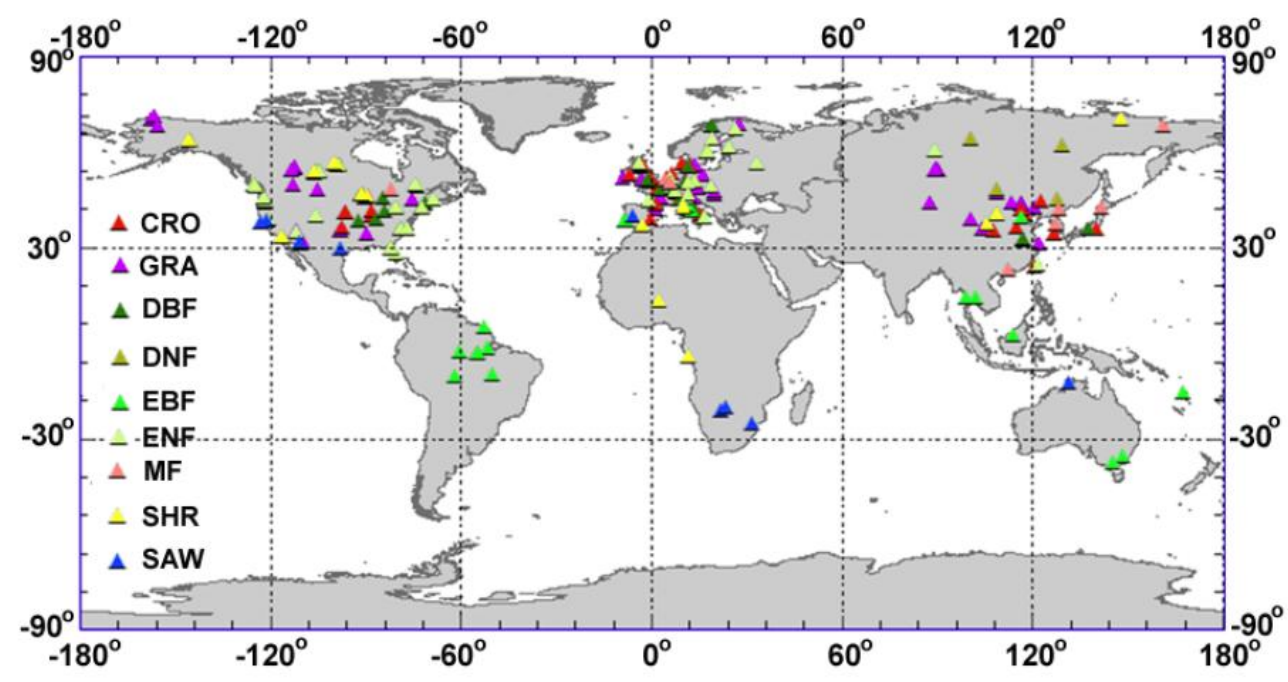


Figure 2
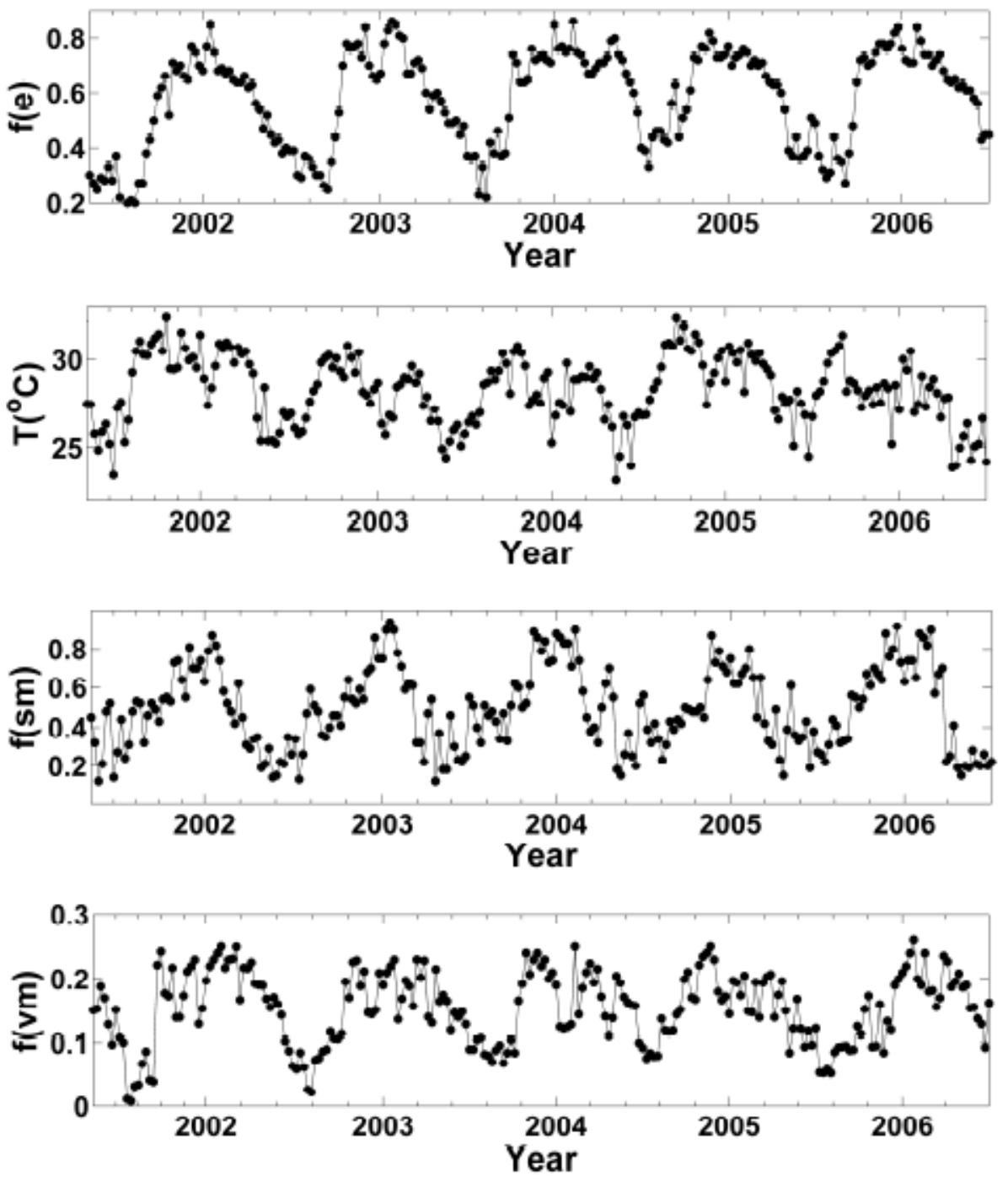
Figure 3
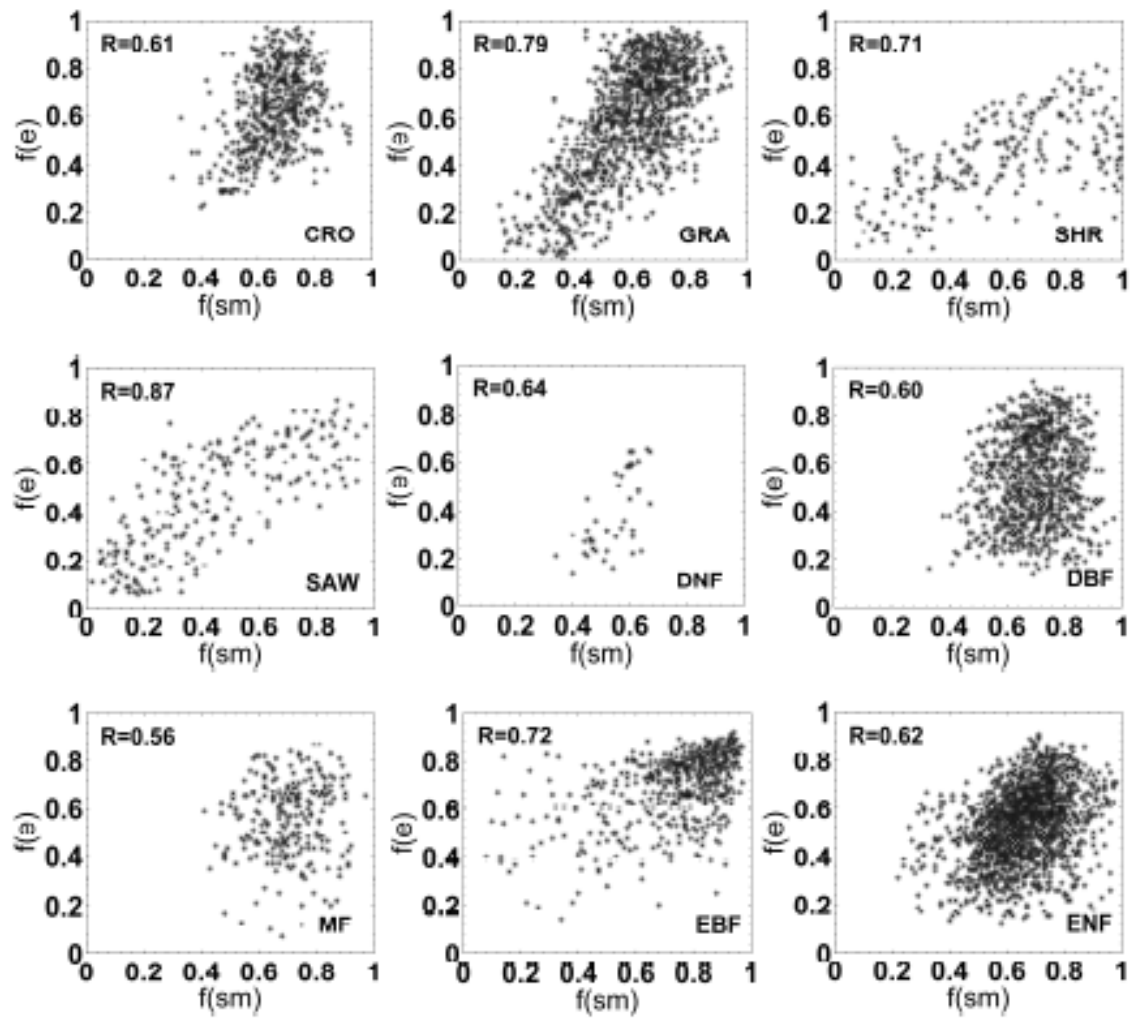
Figure 4
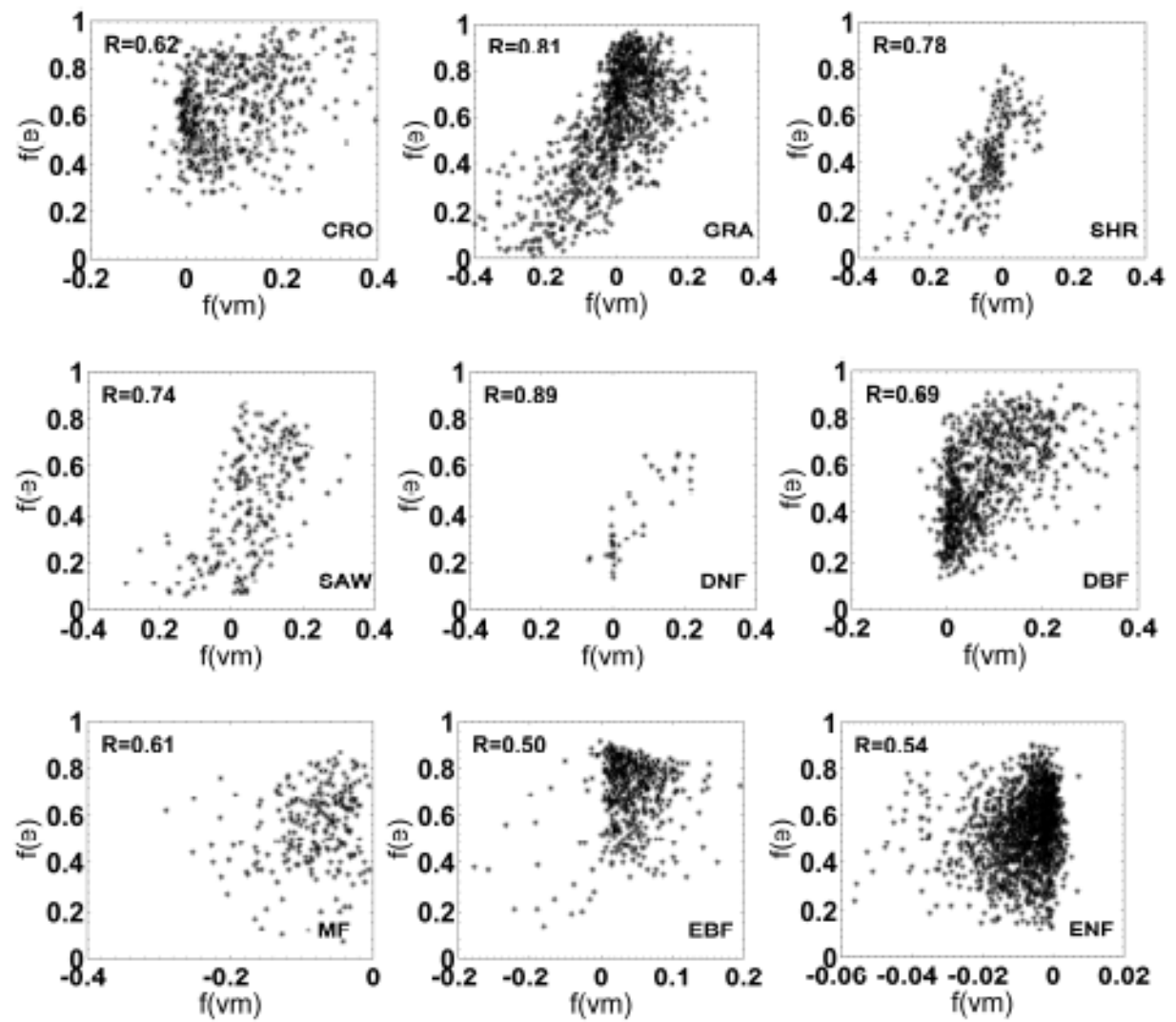
Figure 5
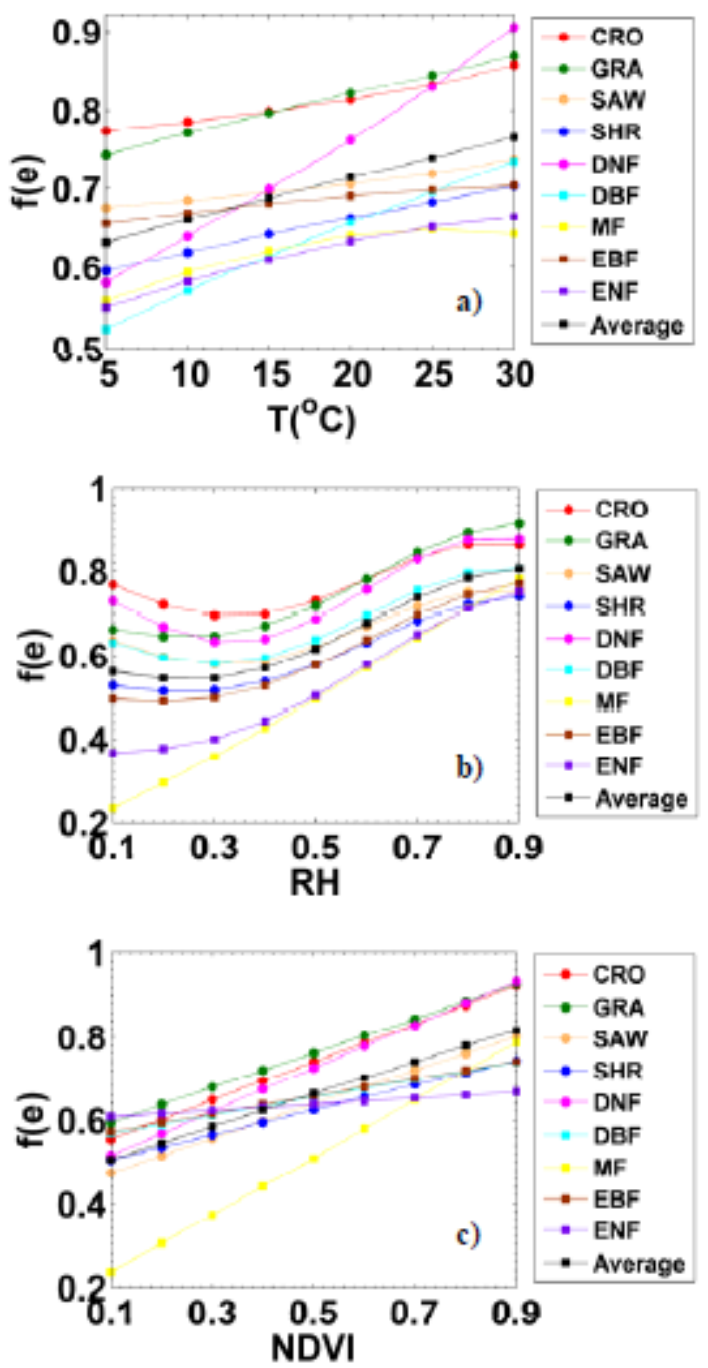
Figure 6
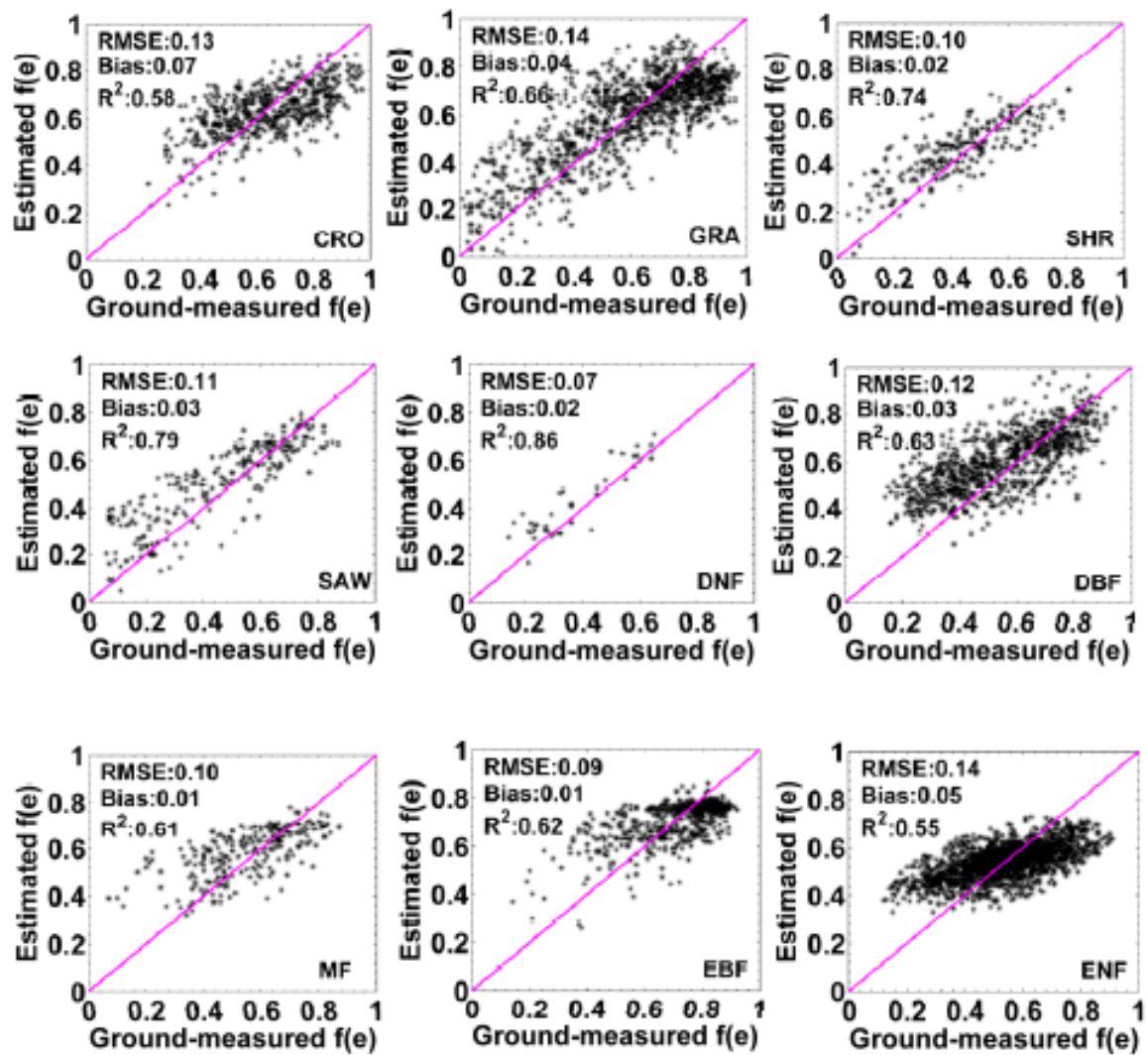
Figure 7.1
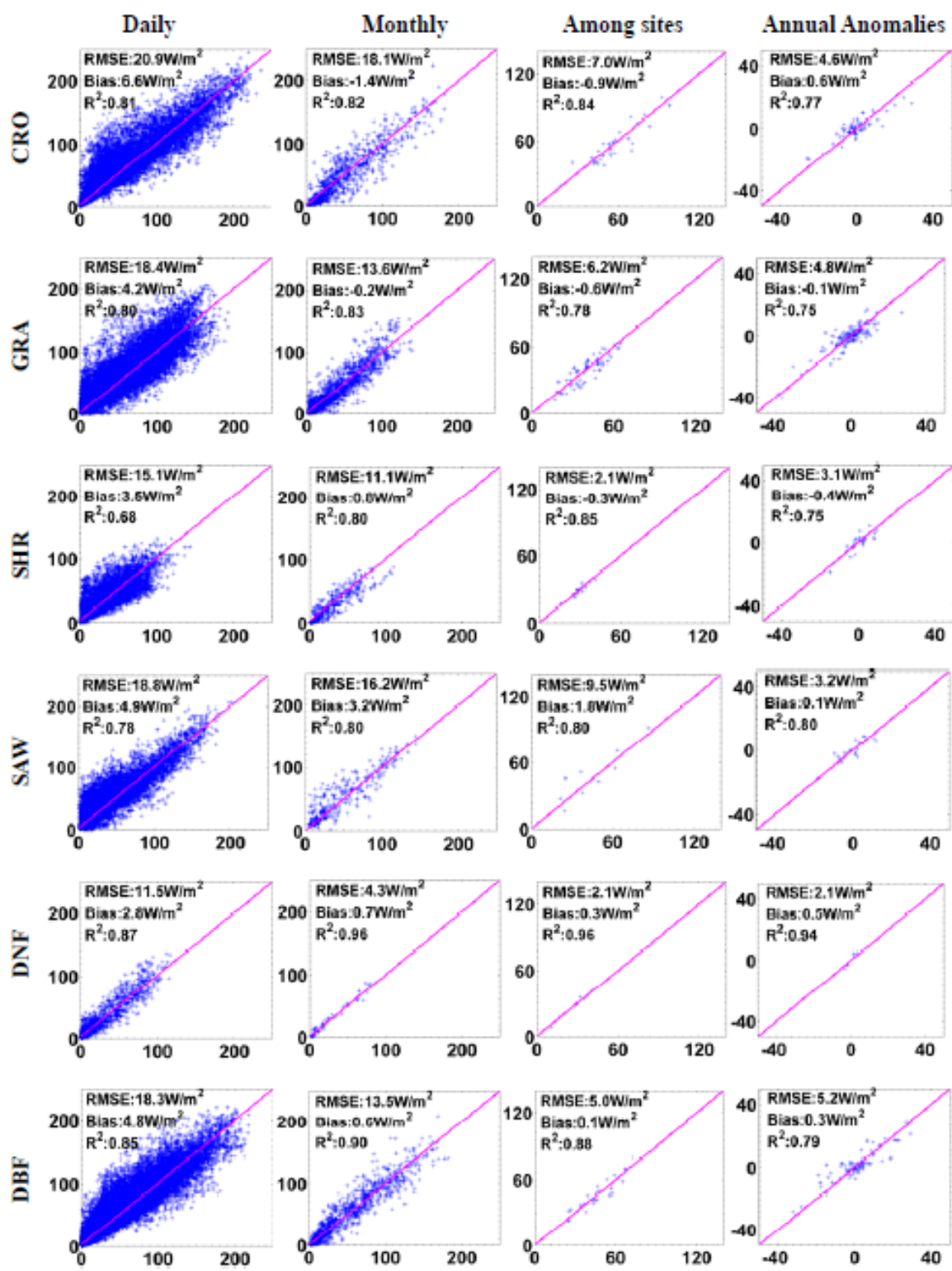
Figure 7.2
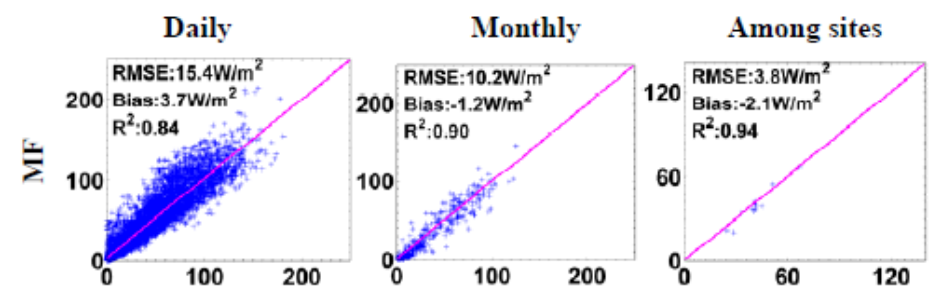

Annual Anomalies
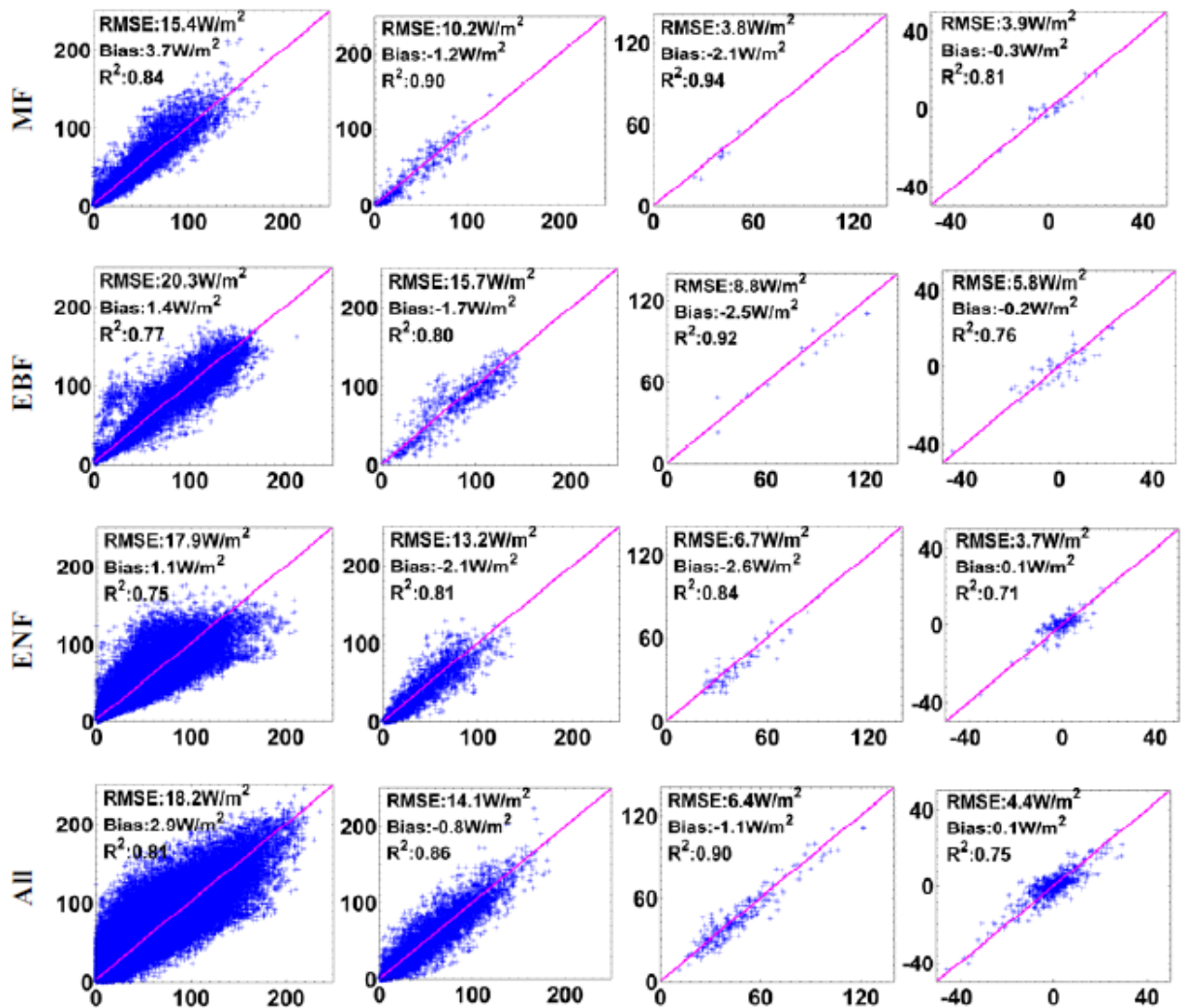
Figure 8
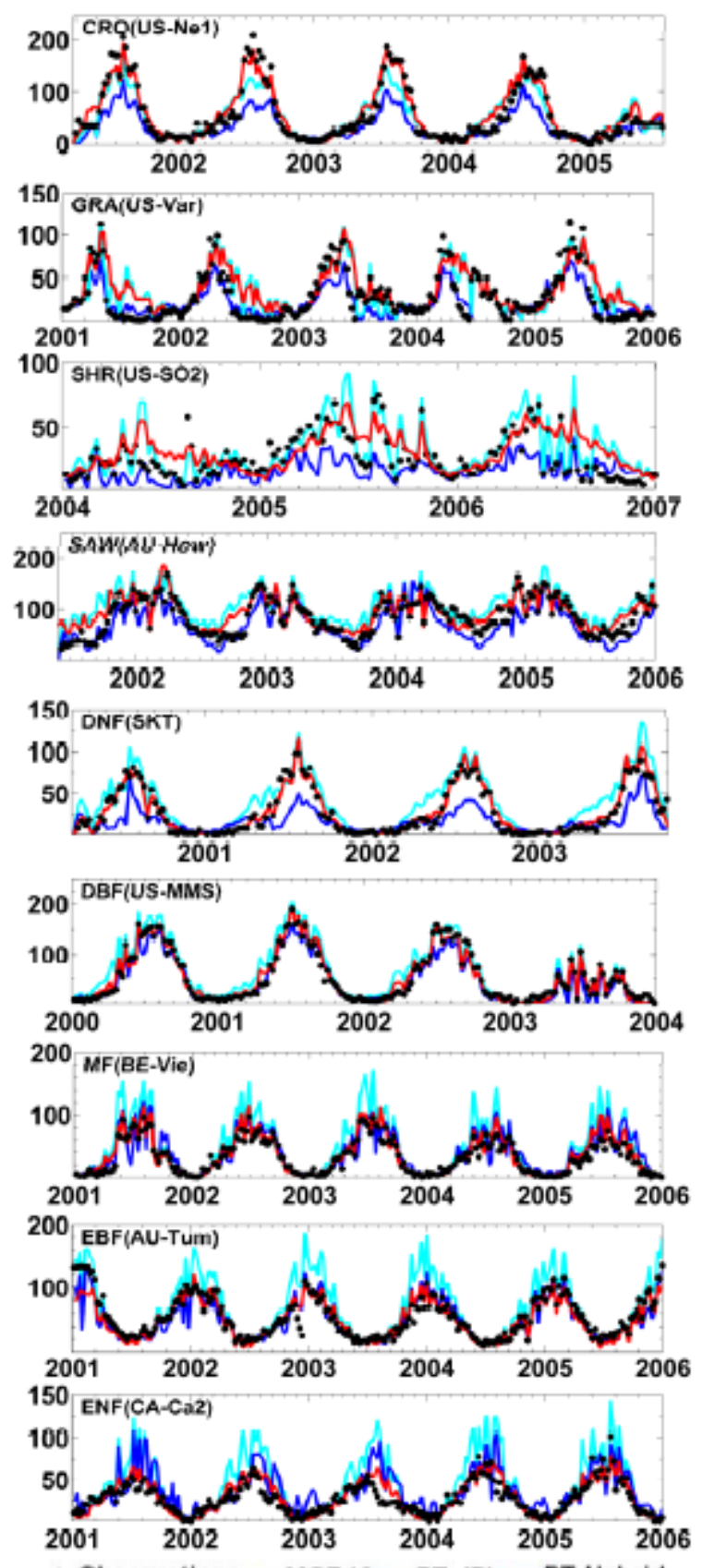

- Observations - MOD16 - PT-JPL — PT-Hybrid 
Figure 9
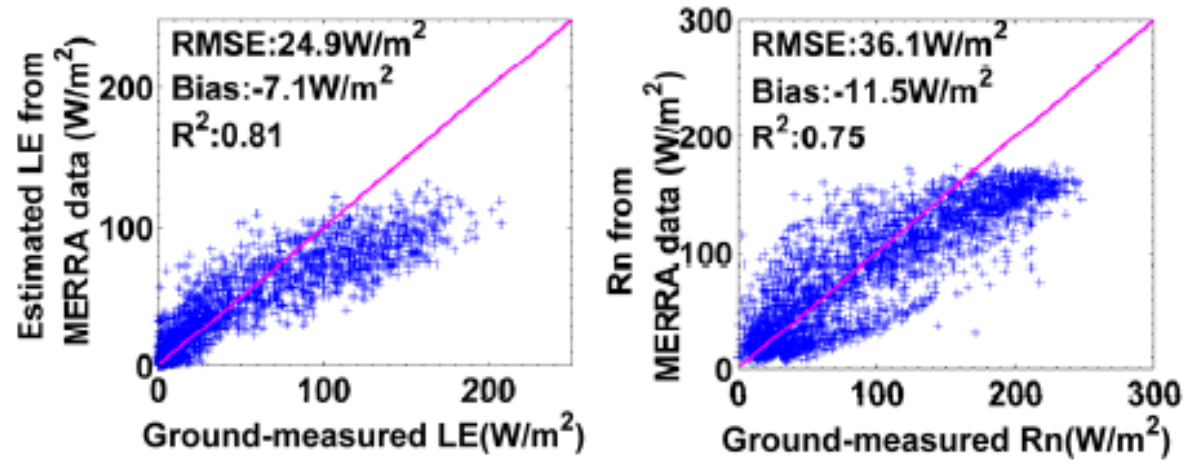
Figure 10.1
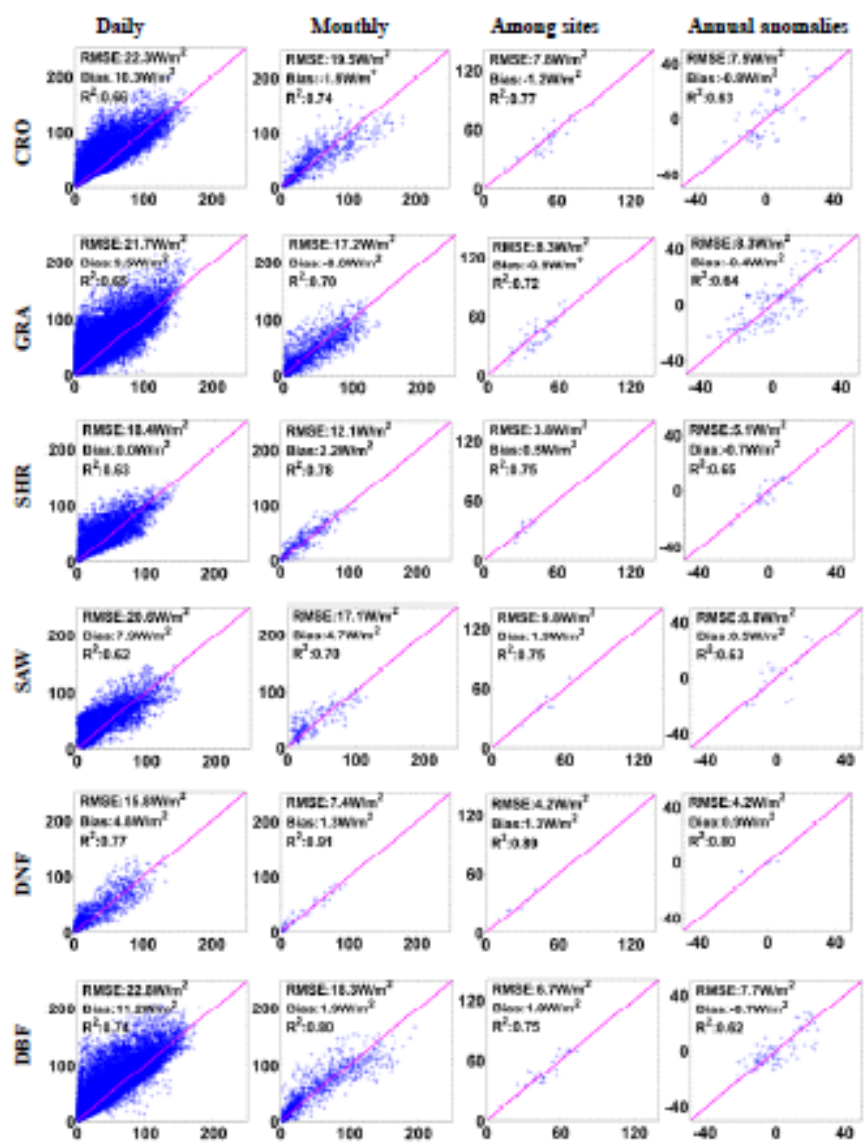
Figure 10.2
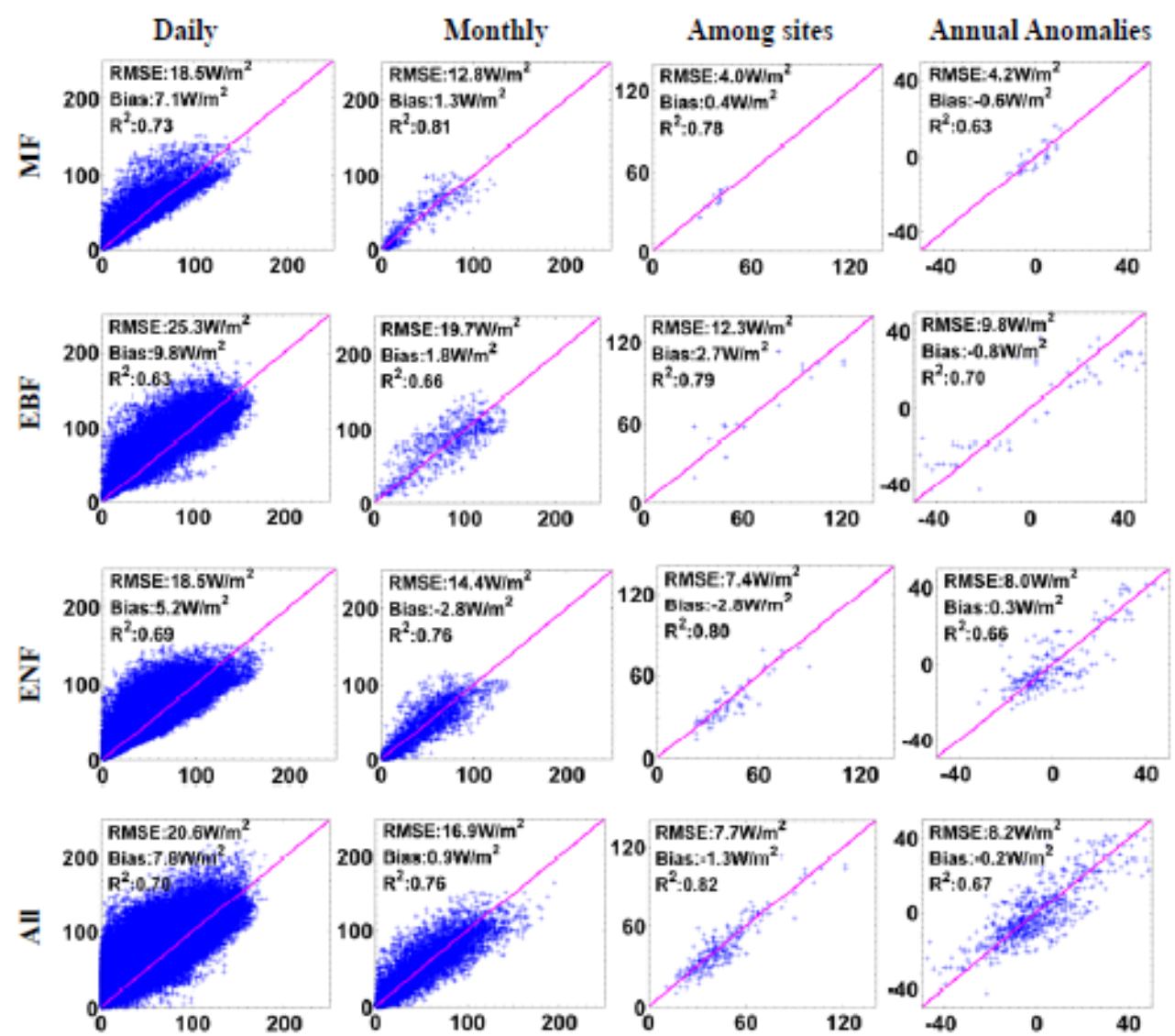
Figure 11

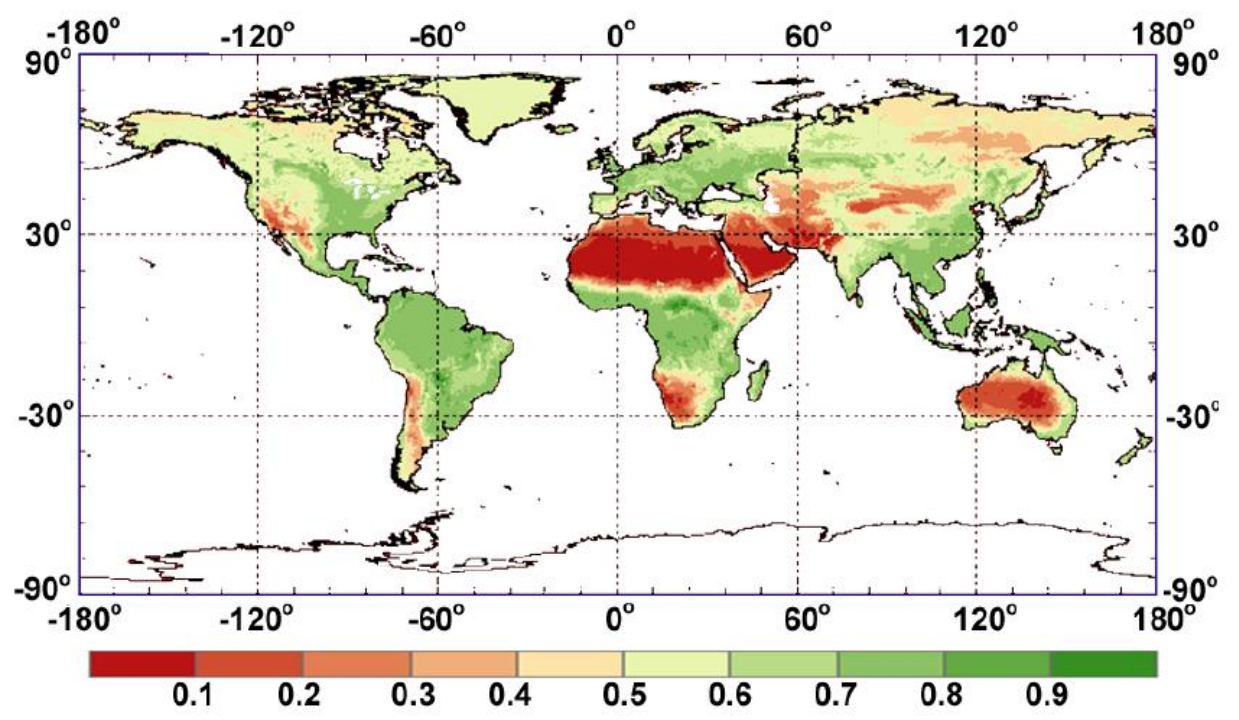


Figure 12

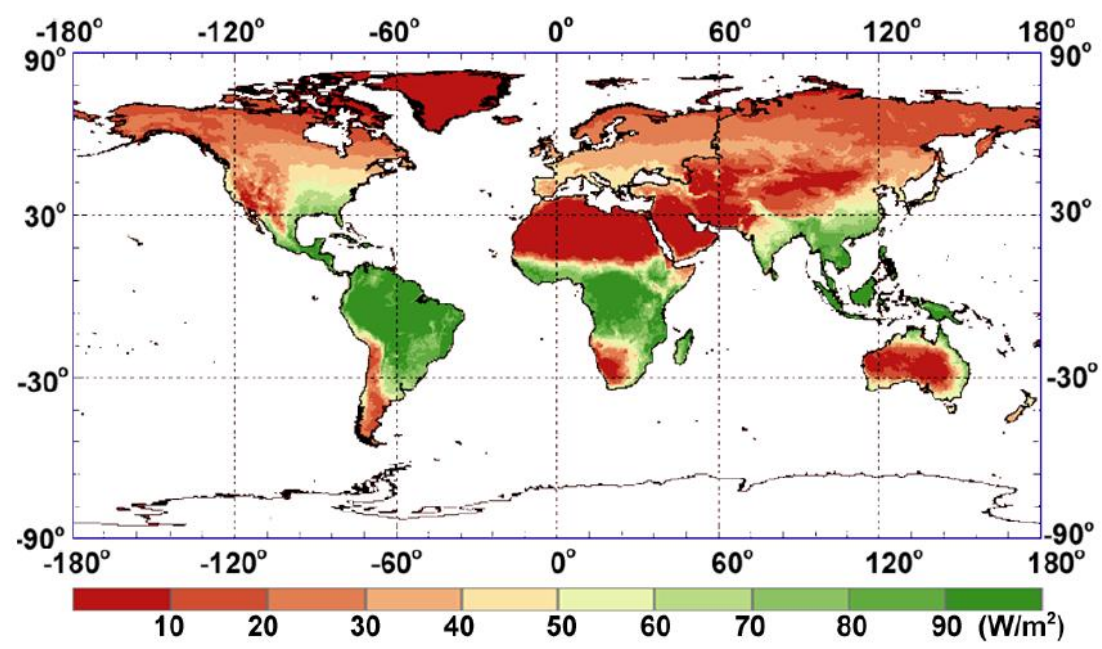


Figure 13

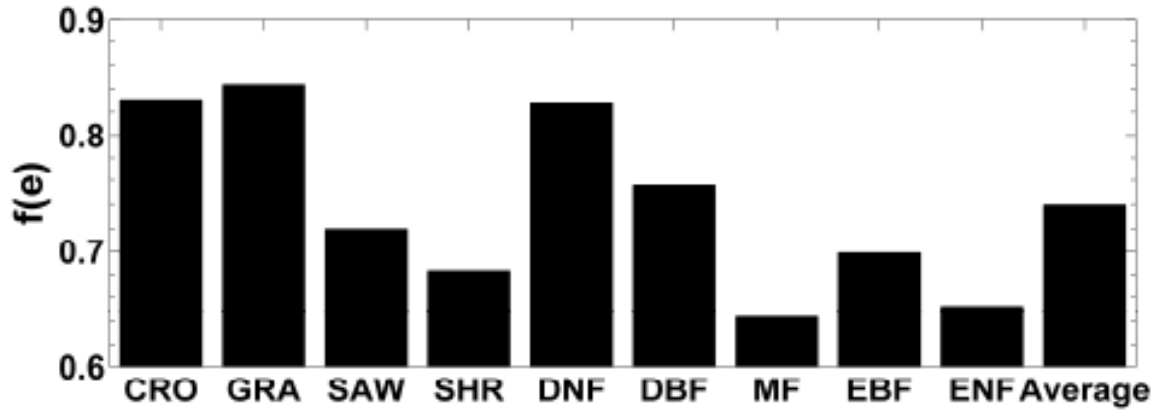


Figure 14

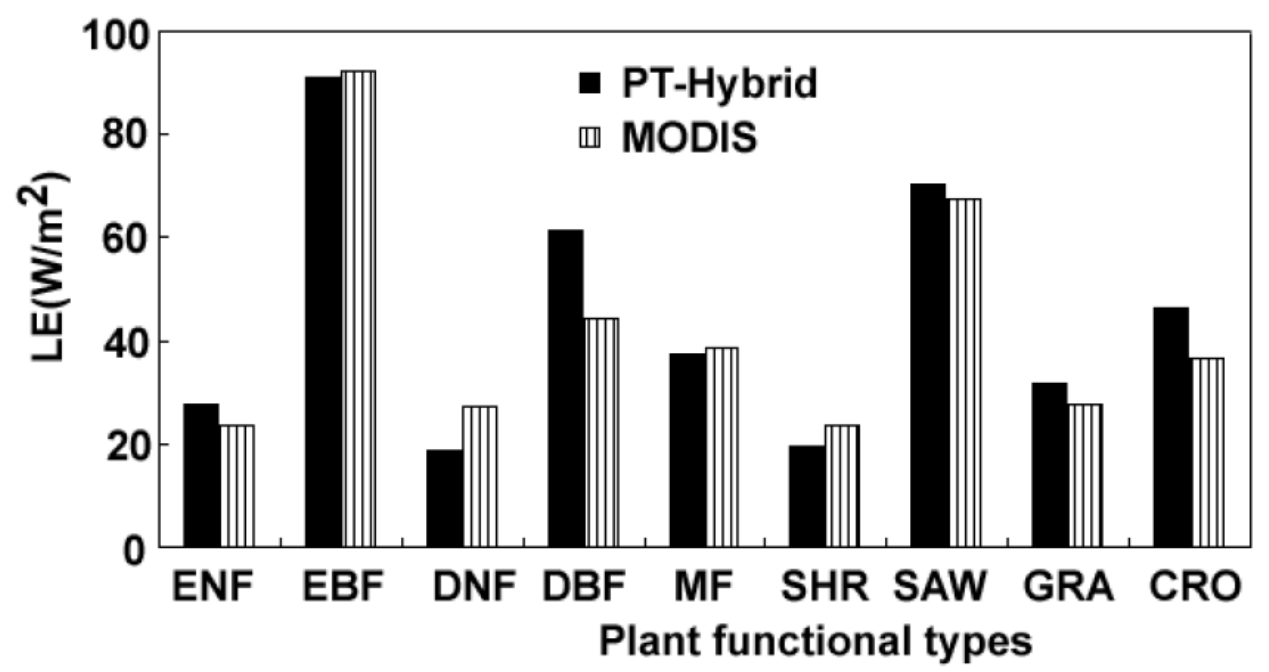

